NBSIR 74.481

Absolute Calibration of Vibration Standards by the Three-Mass Reciprocity Method

John D. Ramboz

Vibration Section, Mechanics Division Institute for Basic Standards National Bureau of Standards

Washington, D. C. 20234

April 1974

Final Report

Prepared for

Department of Defense

Calibration Coordination Group 

NBSIR $74-481$

ABSOLUTE CALIBRATION OF VIBRATION
STANDARDS BY THE THREE-MASS
RECIPROCITY METHOD

John D. Ramboz

Vibration Section, Mechanics Division

Institute for Basic Standards

National Bureau of Standards

Washington, D. C. 20234

April 1974

Final Report

Prepared for

Department of Defense

Calibration Coordination Group

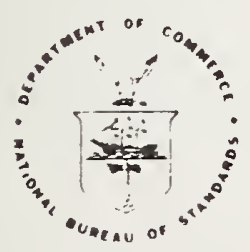

U. S. DEPARTMENT OF COMMERCE, Frederick B. Dent, Secretary NATIONAL BUREAU OF STANDARDS, Richard W. Roberts, Director 


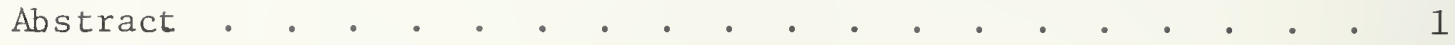

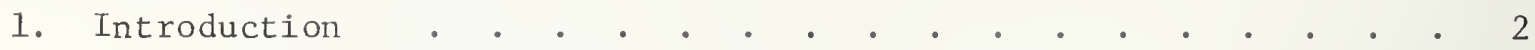

1. 1 Historical Development of Reciprocity Calibration . . . . 2

1.2 The Three-Mass Reciprocity Method . . . . . . . . . 3

1.3 The Power-Balance Reciprocity Method . . . . . . . . 4

1.4 Subsequent Discussion of Three-Mass Method . . . . . . 4

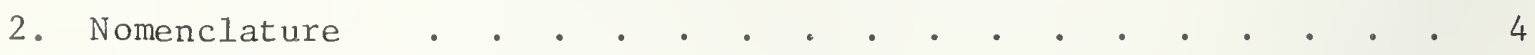

3.'Three-Mass Reciprocity Theory • • • . • . . • • • . . 6

4. Electrical Characteristics of An Electrodynamic Vibration

Exciter • • • • • • • • • • • • • • • . . 10

5. Impedance Measurement Apparatus and Procedure . • • • • . 12

6. Sensitivity Measurement Results . • • • • • • • • . 17

6.1 Measurement Preparation and Precautions . . . . . . . 17

6.2 Measurement Analysis . . . . . . . . • . . . . 18

7. Other Reciprocity Methods Intercomparisons . • • . • • . 24

7.1 Three-Mass and Bouche-Levy Reciprocity Methods . . . . . 24

7.2 Power-Balance and Bouche-Levy Methods . • . . . . . 25

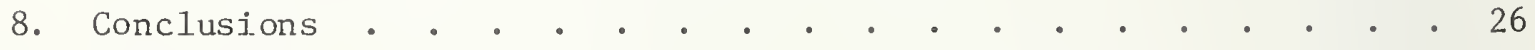

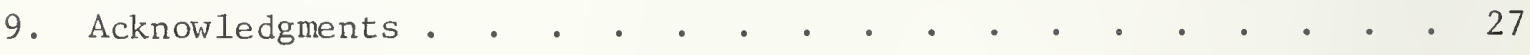

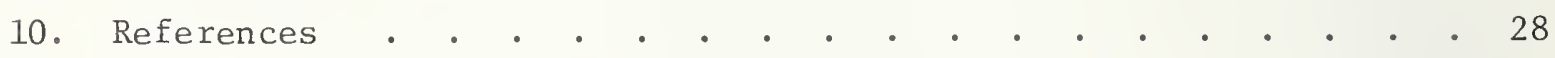

Appendix • • • • • • • • • • • • • • • • 


\section{ABSOLUTE CALIBRATION OF VIBRATION STANDARDS BY THE THREE-MASS RECIPROCITY METHOD}

by

John D. Ramboz

\section{ABSTRACT}

Reciprocity calibration of electrodynamic vibration exciters is reviewed. A new method is proposed. The theory for the new Three-Mass reciprocity calibration method is developed. The process requires that the electrical impedance of the exciter's drive coil be measured for three added masses separately mounted on the exciter's armature. The sensitivity of the accelerometer mounted in the armature is solved in terms of a change of electrical impedance for a change of mass, voltage ratio, electrical resistance, and frequency. A set of 38 measurements were made at $1000 \mathrm{~Hz}$ to experimentally verify the theory. The value of sensitivity was $2.070 \mathrm{pC} / \mathrm{g}$ \pm 1.3 percent. This agreed to within about \pm 0.65 percent of a transfer calibration from Bouche-Levy calibrated standards and the manufacturer's estimated value. Measurements were made to verify the theory; improvement to an uncertainty of about \pm 0.2 percent is ultimately possible in the absolute calibration using this method.

\section{UNITS OF MEASURE}

In this report, SI units are used throughout with the exception of acceleration which is expressed in gravitational units of $g$. This was done to facilitate communication with intended reader. Conversion to SI units may be accomplished using the following relationship: $1 \mathrm{~g}=9.80665$ $\mathrm{m} / \mathrm{s}^{2}$.

\section{KEY WORDS}

Absolute calibration, accelerometers, calibration, reciprocity calibration, vibration exciters, vibration pickups, vibration standards. 


\section{INTRODUCTION}

\subsection{Historical Development of Reciprocity Calitration}

The absolute calibration of vibration reference standards is of fundamental importance to the field of vibration metrology. Absolute calibration methods have been devised, each having its set of limitations and advantages. To date, there is no one method that satisfies the wide range of requirements of vibration frequency, amplitude, waveform, and other associated vibration parameters.

By definition, an electromechanical vibration pickup's sensitivity is the ratio of its electrical output to the input vibration motion driving the pickup along some specified axis. Measuring the electrical output is seldom any serious problem; however, determining the input mechanical motion (vibration) can be difficult. For dynamic calibrations, one or more of three common methods is used: 1) direct measurement of the vibration displacement, 2) direct measurement of the vibration velocity, and 3) reciprocity measurements.

Displacement measurements range from simple direct optical methods to those which utilize complex interferometric methods. Velocity sensing usually makes use of a direct observation and computable elements or sensing a Doppler frequency shift of an optical signal.

Reciprocity methods have been discussed in the literature for many years. The first successful reciprocity calibration of vibration pickups is usually credited to Trent [1] in 1948 who adopted the similar theory and early methods described by Cook [2] in 1940 for the reciprocity calibration of electroacoustic transducers (i.e., microphones). At about the same time, London [3] was developing the method independently from Trent and published his results in early 1948. The advantage of the reciprocity methods thus developed over other calibration methods was that the calibration factor required the measurement of only frequency, mass, and electrical quantities. It was not severely restricted to the low frequencies that the optical displacement method then had imposed.

Thompson $[4,5,6,7]$ corrected Trent's earlier work and applied the method in the velocity calibration of three specially built electrodynamic vibration transducers. His work demonstrated the thoroughness and correctness of the reciprocity theory. Harrison, et al, [8,9] later reported results to frequencies as high as $10 \mathrm{kHz}$.

[1] Numbers in brackets refer to references at the end of this paper. 
All of the above workers reported having severe problems when connecting the mechanical elements into the circuit. Each had used separate and similar type transducers for the experiments. As such, the masses were usually added between the transducers. Alignment was critical and adjusting it was difficult. Camm [10] in 1953 applied the previous knowledge to an electrodynamic vibration excitor having two driver coils and a velocity coil built into one rugged structure. The permanent mechanical connection of the three coils reduced the alignment problems leaving only the masses to be mounted. In 1955, Bouche and Levy [11,12] extended the theory used by Camm to account for the pickup mass and the flexibility of the internal structure of the exciter's drive coil, sensing coil, and mounting table. The refinements that Bouche and Levy incorporated remained the only improvements for several years. In 1965, Bouche and Ensor [13] developed a method with refinements using a piezoelectric pickup as the signal generator rather than a velocity coil. Payne [14] described this method in 1967 and made extensive use of a time-shared computer to collect and analyze the data. In 1968, Sheeks [17] showed that certain simplifications could be made on the theory for a selected vibration exciter. This reduced the amount of calculations needed.

All of the work up to this point required three transducers to perform reciprocity. Coupling problems sometimes precluded any success of a reciprocity calibration. Furthermore, results from reciprocity calibrations at higher frequencies seriously disagreed with interferometric displacement measurement results, the latter being developed by Edelman, Smith, Jones, Pierce, and Schmidt $[15,16]$ in the late $1950^{\prime}$ 's and early 1960's.

\subsection{The Three-Mass Reciprocity Method}

In 1965, Edelman proposed a so-called "self-reciprocity" method [18] requiring only one transducer instead of three. Theoretically, an electrodynamic vibration exciter could be calibrated by absolute means without the need of either a second coil (or vibration exciter) or a separate sensing transducer (such as a velocity coil or a piezoelectric accelerometer).

The Three-Mass reciprocity method required the measurement of the electrical impedance of the driving coil of the exciter while each of three masses were mounted on the table. The sensitivity of the exciter could then be derived from the components of the impedance, driving voltage, and the frequency.

In 1966, Ramboz [19] verified the theory and made preliminary measurements to ascertain the feasibility of such calibrations. It was then realized that the procedure would be difficult because of the relatively small impedance changes of the drive coil as a result of large mass changes on the table. 


\subsection{The Power-Balance Reciprocity Method}

The Power-Balance reciprocity method was first proposed by Uicker and Bain in 1965, and later documented in 1966 [20]. It makes use of the same measurements as the Bouche-Levy method. However, the assumptions made in developing the theory are different, and the mathematical manipulation of the data is different. Data taken by Uicker showed good agreement with the Bouche-Levy method at lower frequencies, but there were unexplained differences at the higher frequencies (above about $2000 \mathrm{~Hz}$ ).

\subsection{Subsequent Discussion of Three-Mass Method}

The subsequent discussions of the Three-Mass reciprocity method given herein are directed to the fundamental theory, the electrical impedance measuring bridges developed, the actual measurement results, and the problems and limitations of the Three-Mass method. Comparisons between the Bouche-Levy and Power-Balance methods are given.

\section{NOMENCLATURE}

The following lists are symbols and nomenclature used in this report. Common and accepted abbreviations are not given, for example mV meaning millivolts, pC meaning picocoulombs, etc.

\section{Symbol}

$$
\mathrm{C}_{\phi}, \mathrm{C}_{\phi \ell}
$$

D

$\mathrm{E}^{\mathrm{p}}, \mathrm{E}_{\ell}^{\mathrm{p}}$

$E^{S}, E_{\ell}^{S}$

$\mathrm{F}$

$I_{\ell}$

$M_{\ell}, M_{a}, M_{b}, M_{c}$

$\mathrm{M}_{\mathrm{ba}}$

$\mathrm{M}_{\mathrm{ca}}$

$\mathrm{M}_{\mathrm{cb}}$

$\mathrm{R}_{\phi}, \mathrm{R}_{\phi \ell}$

$\mathrm{R}_{\mathrm{S}}$

\section{Nomenclature}

Capacitance of bridge balancing circuit element.

Bridge detector.

Acceleration pickup output, usually the output of an amplifier, such as a charge amplifier.

Voltage drop across resistor $\mathrm{R}_{\mathrm{s}}$.

Force.

Drive-coil current.

Added mass load to the exciter's armature.

$\mathrm{M}_{\mathrm{ba}} \equiv\left(\mathrm{M}_{\mathrm{b}}-\mathrm{M}_{\mathrm{a}}\right)$.

$M_{c a} \equiv\left(M_{c}-M_{a}\right)$.

$M_{c b} \equiv\left(M_{c}-M_{b}\right)$.

Bridge balancing resistance.

Stanclard four-terminal resistance of the bridge reference immittance. 

$S^{a}, s_{\ell}^{a}$
Exciter acceleration sensitivity with mass load $\ell$.
$\mathrm{S}^{\mathrm{p}}, \mathrm{S}^{\mathrm{p}}$
$\mathrm{T}_{1}, \mathrm{~T}_{2}$
$\mathrm{T}_{\mathrm{d}}$
$\mathrm{V}$
$\mathrm{X}_{\ell}$
$Z_{\ell}, Z_{a}, Z_{b}, Z_{c}$
$a, b, c$
e
$\mathrm{f}$
$\mathrm{f}_{\mathrm{r}}$
far
g
j
$k_{\ell}, k_{a}, k_{b}, k_{c}$
$\ell$
$\mathrm{p}_{\ell}$
$\alpha_{11}, \alpha_{12}, \alpha_{21}, \alpha_{22}$
$\pi$
$\phi, \phi_{\ell}$
$\sigma$
$\omega$
Acceleration pickup sensitivity with mass load $\ell$.
Precision ratio transformers.
Bridge detector bridging transformer.
Drive-coil velocity with mass load $\ell$.
Drive-coil reactance with mass load $\ell$.
Drive-coil impedance with mass $\mathrm{M}_{\ell}, \mathrm{M}_{a}, \mathrm{M}_{b}$ or $\mathrm{M}_{c}$, respectively.
Subscripts for designating masses, impedances, etc.
Bridge excitation voltage.
Frequency
Electrical resonance frequency of an electrodynamic vibration exciter principally due to the flexure stiffness and armature mass.
Electrical antiresonance frequency of an electrodynamic vibration exciter due to electrical and mechanical impedances.
Standard acceleration of gravity, $1 \mathrm{~g}=9.80665 \mathrm{~m} / \mathrm{s}^{2}$.
Imaginary operator, $j=\sqrt{-1}$
Ratio transformer setting for bridge balance with mass $\mathrm{M}_{\ell}, \mathrm{M}_{\mathrm{a}}, \mathrm{M}_{\mathrm{b}}$ or $\mathrm{M}_{\mathrm{c}}$.
Subscript for designating mass load, $\ell=$ arbitrary mass or $l=a, b$, or $c$.
Same as $k_{\ell}$ except for second ratio transformer.
Four-pole network parameters.
$\pi=3.14159$
Phase angle.
Standard deviation.
$\omega=2 \pi \mathrm{f}$. 


\section{THREE-MASS RECIPROCITY THEORY}

An electrodynamic vibration exciter can be described by four-pole representation of the electrical input, the mechanical output, and the four-pole parameters. Additionally, a mechanical load can be attached to the output of the vibration generator and the resulting four-pole representation will describe the whole electromechanical system of the exciter and load. [21,22,23] Figure 1 shows the representation of an electrodynamic vibration exciter having electrical input terminals with a rigidly attached mass to its output. The input parameters are voltage and current and the output of the system is force and velocity. The specific four-pole equations which mathematically describe the whole electromechanical system of the vibration exciter and mass load are:

$$
\begin{aligned}
& E_{\ell}=\alpha_{11} F+\left(j w M_{\ell} \alpha_{11}+\alpha_{12}\right) V_{\ell}, \\
& I_{\ell}=\alpha_{21} F+\left(j w M_{\ell} \alpha_{21}+\alpha_{22}\right) V_{\ell} .
\end{aligned}
$$

where $E_{\ell}$ and $I_{\ell}$ are the electrical voltage and current inputs to the system $F$ and $V_{\ell}$ are the mechanical force and velocity outputs, $M_{\ell}$ is the load mass ${ }^{l}$, $\omega$ is the angular frequency ( $\omega=2 \pi f$ where $f$ is the frequency in hertz), and $\alpha_{11}, \alpha_{12}, \alpha_{21}$, and $\alpha_{22}$ are the four-pole parameters of the system.

One external force exerted on the armature is the reaction due to the radiation of sound and is shown as the term $F$ in eqs. 1 and 2 . An additional force due to the motion of the armature and its associated mass is shown in the same equations as the product $\left(j \omega M_{\ell}\right) V_{\ell}$. It is desireable that $\mathrm{F}<<\left(j \omega \mathrm{M}_{\ell}\right) \mathrm{V}_{\ell}$. It can be shown using common vibration exciters that $F$ is at least $1000^{\ell}$ times less than $\left(j \omega M_{\ell}\right) V_{\ell}$. In order to simplify subsequent calculations, the acoustic reaction force, F, in eqs. 1 and 2 is thus considered negligible.

The inverse transfer function (inverse sensitivity factor) of the vibration exciter can be defined as the ratio of the input current to the output velocity. Letting $F=0$ in eq. 2 and dividing by $V_{\ell}$,

$$
S_{\ell}^{V}=\frac{I_{\ell}}{V_{\ell}}=j \omega M_{\ell} \alpha_{21}+\alpha_{22} \text {. }
$$

The superscript " $\mathrm{v}$ " Indicates that the sensitivity is in terms of velocity; in mks units, the sensitivity has units of amperes second per meter.

1 The mass expressed throughout these equations is the sum of the armature mass, the load mass, and some portion of the flexure support systems, cables, etc. As will be shown, the final solution is in terms of only the difference of the summation of the masses. Thus, the mass of the armature, etc. subtracts to zero leaving only the added load mass in the solution. $\mathrm{M}_{\ell}$ is used in order to simplify the following expressions. 
The electrical impedance of the drive coil of the vibration exciter can be written as the ratio of eqs. 1 and 2 (again letting $F=0$ ), as

$$
Z_{\ell}=\frac{E_{\ell}}{I_{\ell}}=\frac{j \omega M_{\ell} \alpha_{11}+\alpha_{12}}{j \omega M_{\ell} \alpha_{21}+\alpha_{22}} .
$$

The impedance $Z_{\ell}$ is the electrical impedance of the drive coil with an added mass load, $\mathrm{Ni}_{\ell}$, mounted on the table. If this impedance is measured for each of three different masses, $M_{a}, M_{b}$, and $M_{c}$ in place of $M_{\ell}$, then the three following equations are obtained from eq. 4.

$$
\begin{aligned}
& j \omega M_{a} \alpha_{11}+\alpha_{12}-z_{a} \alpha_{22}=j \omega M_{a} z_{a} \alpha_{21}, \\
& j \omega M_{b} \alpha_{11}+\alpha_{12}-z_{b} \alpha_{22}=j \omega M_{b} z_{b} \alpha_{21}, \\
& j \omega M_{c} \alpha_{11}+\alpha_{12}-z_{c} \alpha_{22}=j \omega M_{c} z_{c} \alpha_{21} .
\end{aligned}
$$

Equations $5 \mathrm{a}, 5 \mathrm{~b}$, and $5 \mathrm{c}$ can be solved for $\alpha_{11}, \alpha_{12}$, and $\alpha_{22}$ in terms of $a_{21}$, and results in eqs. 6,7 , and 8 below.

$$
\begin{aligned}
& \alpha_{11}=-\alpha_{21} \frac{Z_{b} Z_{c} M_{b c}+Z_{c} Z_{a} M+Z_{a} Z_{b} M_{a b}}{Z_{a} M_{b c}+Z_{b} M_{c a}+Z_{c}{ }_{a b}}, \\
& \alpha_{12}=j \omega \alpha_{21} \frac{M_{a} Z_{b} Z_{c} M_{b c}+M_{b} Z_{c} Z_{a} M_{c a}+M_{c} Z_{a} Z_{b} M_{a b}}{Z_{a} M_{b c}+Z_{b} M_{c a}+Z_{c}{ }^{M} a b}, \\
& a_{22}=-j w a_{21} \frac{M_{a} Z_{a} M_{b}+M_{b} Z_{b} M a}{Z_{a} M_{c} Z_{c} M_{a b}}
\end{aligned}
$$

The notation of the double subscripts indicates that $\mathrm{M}_{a b} \equiv\left(\mathrm{M}_{a}-\mathrm{M}_{b}\right)$, $M_{b c} \equiv\left(M_{b}-M_{c}\right)$ and $M_{c a} \equiv\left(M_{c}-M_{a}\right)$. Using an established relationship from reciprocity theory for an electromagnetic system ${ }^{2}$, and applying it to the electrodynamic vibration exciter as a linear and bilateral device, it has been shown that the following relationship must hold in order for reciprocity to be valid: [21,22]

$$
\alpha_{11} \alpha_{22}-\alpha_{12} \alpha_{21}=1 \text {. }
$$

2 The application of the reciprocity theorem has been extensively discussed in references $1,3,4,5,6,7,21,22,23$ and 24, among others.

This previous work will be accepted and no proof will be given here. 
Substituting the values of $\alpha_{11}, \alpha_{12}$, and $\alpha_{22}$ from eqs. 6 through 8 into eq. 9, the solution for $\alpha_{21}$ is

$$
\alpha_{21}=\frac{z_{a} M_{b c}+Z_{b} M_{c a}+Z_{c} c_{a b}}{\left(j \omega M_{a b}{ }^{M} c^{M}{ }_{c a}{ }^{2} b_{b c} Z_{c a}\right)^{1 / 2}} \text {, }
$$

where the notation of the double subscripts for the impedances specifically imply an impedance difference and are similar as previously described above for the masses. Substituting eq. 10 into eq. 8 the necessary four-pole parameter $\alpha_{22}$ can be determined and is

$$
\alpha_{22}=\frac{-(j \omega)^{1 / 2}\left(M_{a} Z_{a} M_{b c}+M_{b} Z_{b} M_{c a}+M_{c} Z_{c} M_{a b}\right)}{\left(M_{a b} M_{b c}{ }_{c a} Z_{a b} Z_{b c} Z_{c a}\right)^{1 / 2}} .
$$

Finally, substituting eqs. 10 and 11 into eq. 3, the solution for the current sensitivity of the system can be obtained as

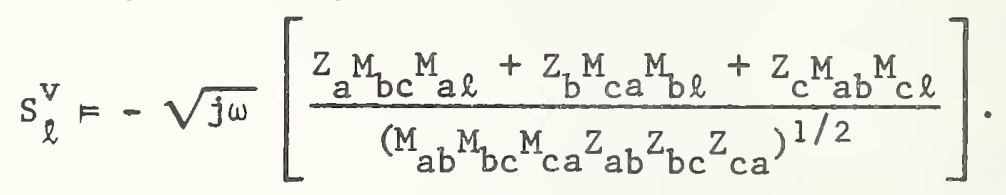

The above expression is the inverse transfer function in terms of the vibration exciter's velocity. Determination of $\mathrm{S}_{l}^{\mathrm{V}}$ requires that the impedances $Z_{a}, Z_{b}$ and $Z_{c}$ be measured for each of the three masses, $M_{a}, M_{b}$ and $M_{c}$, mounted separately on the vibration exciter.

Because of the subsequent application and use of the vibration exciter. as a standard, it is desirable to have the sensitivity factor expressed in terms of acceleration rather than velocity. This may be accomplished by dividing eq. 12 by $j w$. Additionally, there is an advantage to have the acceleration expressed in units of the gravitational constant, $g$. Equation 13 gives the acceleration sensitivity factor in units of amperes per unit $g$ when the mass is expressed in units of kilograms, impedance in units of electrical ohms and frequency in hertz. The superscript "a" indicates that the sensitivity is in acceration units.

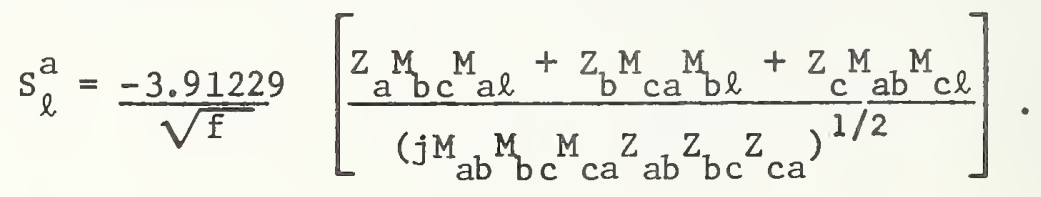


For later operational considerations, it is desirable to incorporate an accelerometer into the vibration exciter so that a "back-to-back" vibration comparisor. can subsequently be made. Also, high quality piezoelectric accelerometers will exhibit a more stable sensitivity factor than that of the driving coil and magnetic field of the vibration exciter. In order to transfer the Three-Mass reciprocity calibration from the drive coil to the acceleration pickup, eq. 13 may be multiplied by the ratio of $\left(E_{\ell}^{P} / I_{\ell}\right)$, such that

$$
S_{\ell}^{p}=S_{\ell}^{a}\left[\frac{E_{\ell}^{p}}{I_{\ell}}\right]
$$

where $\mathrm{S}_{l}^{\mathrm{P}}$ is the acceleration sensitivity factor for the pickup in units of volts per $g, E_{l}^{p}$ is the output voltage of the pickup in volts, and $I_{\ell}$ is the drive-coil $1^{l}$ current in amperes.

The drive coil current can be determined by measuring the voltage drop across a precision four-terminal resistance having a value of $R_{S}$ connected in series with the drive coil. Letting $I_{\ell}=\left(E_{\ell}^{S} / R_{s}\right)$ and substituting it into eq. 14, the pickup sensitivity factor may be expressed as

$$
S_{\ell}^{p}=S_{\ell}^{a}\left[\frac{E_{\ell}^{p}}{E_{\ell}^{s} / R_{S}}\right]=S_{\ell}^{a}\left[\frac{E_{\ell}^{p}}{E_{l}^{s}}\right] R_{S},
$$

where $E_{\ell}^{S}$ is the voltage drop across resistor $R_{S}$. Thus, examination of eq. 13 and 15 shcrs that a vibration pickup can be reciprocity calibrated in terms of the indicated quantities of mass, electrical impedance, frequency, and voltage ratio.

Each of the separate added load masses, $M_{a}$, $M_{b}$ or $M_{c} c a n$ be substituted, in turn, for $\mathrm{M}_{\ell}$. Doing so in eq. 13 and combining the results with eq. 15 yields three relationships for the sensitivity factor of the acceleration pickup. 
Equations 16, 17 and 18 give these relationships. Note that the order of the double subscripts for some of the masses and impedances have been reversed from those previously shown so that the mass radicals are always positive, assuming that $\mathrm{M}_{a}<\mathrm{M}_{b}<\mathrm{M}_{c}$.

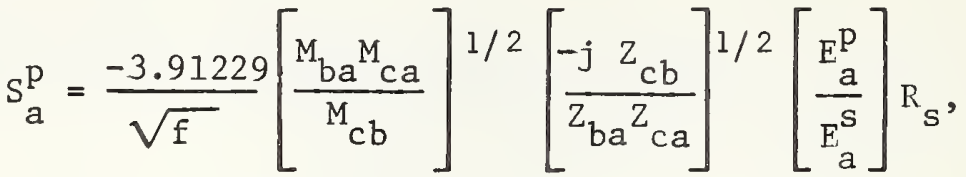

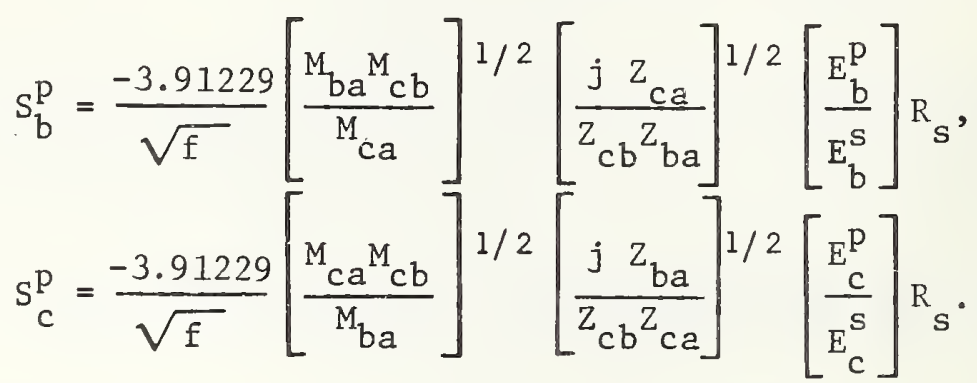

Examination of the above three equations shows that the sensitivity factors are functions of a change of impedance as a result of a change of mass. This important aspect of this derivation reduces the requirements for the measurement of absolute values of impedance and mass to differences of each.

\section{ELECTRICAL CHARACTERISTICS OF AN ELECTRODYNAMIC VIBRATION EXCITER}

An electrodynamic vibration exciter fundamentally consists of a drive coil suspended in an intense magnetic field. Mechanically connected to the coil is an armature and an attachment plane or table. Figure 2 shows a typical arrangement of a vibration generator used for calibration purposes. The magnetic $f 1 u x$ is often provided by a permanent magnet. The magnetic gap is formed by a round center pole piece and the outer pole pieces are generally formed by a plate-like member. The weight of the armature is supported and in some cases also centered by the flexures. To provide a stiffer lateral restraint, hydrostatic bearings have been applied to the armature $[25,26]$.

The drive coil is most often wound with a copper conductor (aluminum sometimes being used) such that when placed in the magnetic gap, an alternating current will cause an alternating reaction force and hence, a motion if unrestrained. The direction will be perpendicular to the magnetic field and parallel to the central axis of the drive coil. A vibration pickup, generally a piezoelectric accelerometer, is mounted as an integral part of the armature and rigidly coupled to the table. The table usually contains one or more tapped holes to provide the easy mounting of mechanical loads. 
As an electrical impedance, the drive coil exhibits a complex combination of the intrinsic electrical properties and coupled mechanical characteristics. Figure 3 a shows a typical plot of drive-coil impedance as a function of frequency. When the armature and drive coil are restrained from moving, the impedance increases from some nearly resistive value at the low frequencies to a highly inductive value at high frequencies. This is primarily due to the resistance of the conductor and the geometric inductance of the coil, and secondarily to skin effect, eddy current losses and the permeability of the pole pieces. For the unrestrained case, a significant difference is noted. A mechanical resonance occurs at some lower frequency, generally less than several hundred hertz. This is the spring-mass resonance resulting from the stiffness of the supporting flexures and the mass of the armature (and mechanical load, if any). The response is generally broad due to the mechanical damping of the flexures and losses in the electrical driving circuit. The electrical impedance change is a function of the external mass (i.e., mechanical impedance) change of the armature. The restrained armature represents an infinate external mass while the unrestrained armature represents no external mass. The electrical resonance is at approximately the same frequency as the mechanical spring-mass resonance.

The electrical impedance of a typical small vibration exciter is shown in figs. $3 a-3 e$. Over the frequency region from zero hertz to the resonance, $0<\mathrm{f}<\mathrm{f}_{\mathrm{r}}$, the electrical impedance is inductively reactive; from the resonance to the antiresonance, $f_{r}<<f_{a r}$, the impedance is capacitively reactive: and above the antiresonance, $f>f$ ar, the impedance again appears inductive. The impedance assumes purely resistive values at three frequencies; at zero hertz, $f=0$, at the resonance, $f_{r}$, and at the antiresonance, $f$. It is interesting and significant to note that the in-phase resistive component of the drive-coil impedance varies through a rather wide range of values. The minimum value of this resistive component occurs at $f=0$ and is generally in the order of several ohms. As the frequency increases, the resistive portion of the impedance increases. At frequencies. of several thousand hertz, values of resistance may reach 7 to 10 ohms or more. This increasing resistance is due principally to eddy-current losses and skin effect. Figure $3 \mathrm{~b}$ shows a typical plot of the resistive component as a function of frequency, for both the restrained and unrestrained conditions. Note how the resistance increases in the region of $f_{r}$. Also note that at the higher frequencies, the resistance is slightly greater when restrained than when unrestrained.

Figure $3 c$ shows the reactive components of the drive-coil impedance. Note that at frequencies of $f_{r}$ and $f_{\text {ar }}$, the reactances are zero. Figure $3 d$ shows typical plots for the values of equivalent inductance and capacitance as a function of frequency. Figure $3 \mathrm{e}$ shows the phase of the impedance vector. 
The above values were obtained using a small vibration exciter having an output rating of a couple force-pounds. Because the armature was rather light, the spring-mass resonance is relatively high. Typical exciters used for calibration work would have more massive armatures thus lowering the resonance significantly. The small exciter with the high resonance frequency did make practical the necessary measurements for impedance, etc. Calibration exciters will exhibit similar characteristics scaled to some lower frequency.

The change of impedance as a function of the restraint is of particular importance in the subsequent discussions regarding Three-Mass reciprocity measurements. As the foregoing discussion shows, at frequencies greater than the antiresonance ( $f_{\text {ar }}$ ), the change of impedance for the unrestrained to restrained cases is small. The restrained condition represents an infinite mass load on the exciter. The unrestrained condition represents a zero mass load. The change of impedance is only a few percent under these extremes of load. This result imposes a serious requirement of precision measurement of the drive-coil impedance since the difference of impedance for different mass loads leads to the final sensitivity solution, as shown by eqs. 16,17 , and 18 .

\section{IMPEDANCE MEASUREMENT APPARATUS AND PROCEDURE}

Examination of eqs. 16, 17, and 18 shows that the solution for the acceleration pickup sensitivity factor requires the measurement of drivecoil impedance while each of three masses are mounted on the exciter table. At any discrete frequency the impedance can be represented as a simple series equivalent resistance and reactance. It would encompass all the electrical and mechanical properties which contribute to the total electrical impedance at this discrete frequency. Figure 4 shows a ratio transformer bridge circuit that will measure the complex impedance that exhibits inductive reactance. Referring to figure 3, this would include the regions between zero hertz and the electrical resonance, and frequencies greater than the antiresonance. The drive coil is connected in series with an adjustable capacitance, $\mathrm{C}_{\phi}$ and with a precision four-terminal resistor, $R_{S}$. The capacitor may be parallel combinations of decade and continuously variable units. The resistor must be of four terminal design capable of carrying the drive-coil current, $I_{\ell}$. The combination of the drive coil and capacitor forms one arm of the bridge, the four-terminal resistor forms a second-bridge arm, and the decade-ratio transformer forms the remaining two arms. The bridge balance is achieved by adjustment of $\mathrm{C}_{\phi}$ and the ratio transformer for a null as indicated by the tuned detector, D. At balance, the capacitive reactance of $\mathrm{C}_{\phi}$ is equal and opposite to the inductive reactance of $\mathrm{Z}_{\ell}$. The impedance may be calculated using the following: 


$$
\begin{gathered}
z_{\ell}=R_{\ell}+j x_{\ell}=R_{s}\left[\frac{\left(1-k_{\ell}\right)}{k_{\ell}}\right]+j\left[\frac{1}{\omega C_{\phi \ell}}\right], \\
\phi_{\ell}=\tan ^{-1} \frac{x_{\ell}}{R_{\ell}}=\frac{k_{\ell}}{\left(1-k_{\ell}\right) \omega C_{\phi \ell}},
\end{gathered}
$$

where $k_{\ell}$ is the ratio transformer setting at balance.

The subscript \& indicates the mass which is mounted on the table while the bridge is being balanced. With mass $\mathrm{M}_{\mathrm{a}}$ mounted, some arbitrary value of $\mathrm{C}_{\phi}$ is selected to provide a path for the drive current, $I_{\ell}$. The current is adjusted to produce the desired operating acceleration, as nominally indicated by the vibration pickup output voltage, $\mathrm{E}_{\ell}^{\mathrm{P}} \cdot$ (This step assumes that the nominal sensitivity of the pickup is approximately known which, in most instances, is a valid assumption.) Thereafter, the series capacitor and the ratio transformer are adjusted such that a null is indicated by the tuned detector. During the operation, it is essential to maintain a constant current, $I_{\ell}$, through the drive coil. The magneticpole pieces exhibit an incremental permeability which is current sensitive. This directly influences the value of the drive-coil reactance. The impedance is a function of the velocity generated counter emf, which is also current sensitive. Thus, if the current was not maintained constant, an undesirable impedance change would occur and be measured. The current can be held constant by monitoring the voltage $E_{l}^{S}$ and by employing a constantcurrent power source. Furthermore, the resistance of the arive coil is temperature sensitive. The temperature coefficient for copper is approximately 4,000 parts per million per degree Celsius. If the drive-coil current were to change by very much, the coil resistance would change due to self heating. These types of impedance changes are not related to the added mass during the measurement, and therefore constitute a measurement error. Impedance changes due to, and due only to, a mass change must be measured.

When a balance has been obtained, the values for $\mathrm{C}_{\phi a}$, ratio transformer setting $\mathrm{k}_{\mathrm{a}}$, and voltages $\mathrm{E}_{\mathrm{a}}^{\mathrm{S}}$ and $\mathrm{E}_{\mathrm{a}}^{\mathrm{P}}$ are recorded. The voltage $\mathrm{E}_{l}^{\mathrm{S}}$ is used as the phase-angle reference. Mass $M_{a}$ is removed and replaced by $M_{b}$ and again the bridge is balanced and values recorded. Finally, $M_{c}$ replaces $M_{b}$ and the third set of measurements are obtained. The value of impedance and the phase angle is computed by use of eqs. 19 and 20. From these three sets of measurements, the pickup sensitivity factor may be calculated from eqs. 16, 17, and 18 above. 
As the mass load is increased on the table, an accompanying decrease in velocity results. This decrease of velocity decreases the back emf, and hence, changes the impedance.

In considering and selecting the masses to be used for the calibration process, some knowledge must be available concerning the effective mass of the armature. For most electrodynamic vibration exciters, the largest of the three masses should approach the mass of the armature. As previously stated, and again referring to figure 3, the impedance change as a function of added mass to the table results in a relatively small change of drivecoil impedance. On some vibration exciters, the impedance change might be too small to afford any reasonable impedance difference measurement. In the frequency region of the spring-mass resonance, smaller values of mass may provide more than adequate changes of impedance for good overall calibrations. The masses may be selected such that $\mathrm{M}_{a}<\mathrm{M}_{b}<\mathrm{M}_{\mathrm{c}}$.

For the bridge configuration shown in figure 4, a typical value of $\mathrm{R}_{\mathrm{S}}$ is 4 ohms and $C_{\phi}$ will range from several microfarads to as high as hundreds of microfarads. Limitations in the use of the above described bridge occur when the inductive reactance becomes small. This requires large values of capacitance. For example, as the frequency is decreased towards the antiresonance ( $f_{\text {ar }}$ in figure 3), a value of more than several hundred microfarads would be required.

At $\mathrm{f}_{\mathrm{r}}$ and $\mathrm{f}_{\mathrm{ar}}$, of figure 3, an infinite capacitance (short circuit) would be needed to achieve a balance. In the region between $\mathrm{f}_{\mathrm{r}}$ and $\mathrm{f}_{\mathrm{ar}}$, the bridge circuit of figure 4 will not work since the impedance is already capacitive, and more capacitance causes additional bridge unbalance.

The circuit shown in figure 5 is capable of measuring either inductive or capacitive reactive impedances. [27] It employs two ratio transformers, $\mathrm{T}_{1}$ and $\mathrm{T}_{2}$, and two phase generating elements, $\mathrm{R}_{\phi}$ and $\mathrm{C}_{\phi} \cdot$ The ratio transformer settings are indicated by $k$ and $p$. Other aspects of the circuit are similar to those concerning the previously discussed bridge circuit of figure 4. At the bridge balance, the unknown impedance, $Z_{\ell}$ is given by

$$
\begin{gathered}
z_{\ell}=R_{\ell} \pm j x_{\ell}=R_{s}\left[\frac{k_{\ell}\left(1-k_{\ell}\right)+p_{\ell}\left(1-p_{\ell}\right)\left(\omega R_{\phi} C_{\phi}\right)^{2}+j\left(k_{\ell}-p_{\ell}\right) \omega R_{\phi} C_{\phi}}{k_{\ell}^{2}+p_{\ell}^{2}\left(\omega R_{\phi} C_{\phi}\right)^{2}}\right], \\
\phi_{\ell}=\tan ^{-1} \frac{x_{l}}{R_{\ell}}=\tan ^{-1}\left[\frac{\left(k_{\ell}-p_{\ell}\right) \omega R_{\phi} C_{\phi}}{k_{\ell}\left(1-k_{\ell}\right)+p_{\ell}\left(1-p_{\ell}\right)\left(\omega R_{\phi} C_{\phi}\right)^{2}}\right] .
\end{gathered}
$$


The subscripts $\ell$ again relates to which one of three masses are mounted on the table. When $\mathrm{P}_{\ell}<\mathrm{k}_{\ell}$, the impedance is inductive; when $\mathrm{P}_{\ell}>\mathrm{k}_{\ell}$, the impedance is capacitive; and when $\mathrm{P}_{\ell}=\mathrm{k}_{\ell}$, the impedance is purely resistive. The values of $R_{s}, R_{\phi}$ and $C_{\phi}$ are selected to bring the balance within the range of $k_{\ell}$ and $P_{\ell}$, which are usually restricted to values between zero and unity. It is again necessary and important to maintain constant value of $I_{\ell}$.

Typical values for $\mathrm{C}_{\phi}$ might be 1000 pf and $\mathrm{R}_{\phi}$ might be 200 kilohms. With such relatively high values of impedance, good shieldirg will be necessary on the detector side of $R_{\phi}$ and $C_{\phi}$. A typical value for $R_{S}$ would be 4 ohms.

In both the foregoing impedance measuring circuits, circuit residuals such as shunting impedances, lead and contact resistances, etc." are included in the measured value of $z_{2}$. Assuming that they remain undisturbed and constant during the time that the three impedances are measured, their contribution will be subtracted to zero when the impedance differences are obtained. Therefore, no extreme precautions are necessary in connecting the drive coil into the measuring circuit.

The above is a direct consequence of expressing the vibration exciter transfer function (inverse sensitivity factor) in terms of amperes per unit velocity. This is shown in eq. 3. Had the transfer function been expressed in terms of the voltage across the exciter (as proposed by Edelman [18]) rather than series current, the sensitivity solution requires a precise and accurate measurement of $z_{l}$, the drive-coil impedance. This would necessitate wiring the drive coil as a four-terminal impedance and employing Wagner earths to balance shunting drive-circuit impedances. Additionally, the effects of the interconnecting link resistance between the low side of the drive coil and the low side of bridge reference impedance, $R_{S}$, would have to be accounted for [27]. These complexities are avoided in the methods present herein.

Ground loop currents may flow easily in the detector branch. In the simple ratio trarsform bridge, the overall impedance is relatively low owing to the low output series impedance of $\mathrm{T}_{1}$ and the low value of $\mathrm{R}_{\mathrm{S}}$. The controlling impedance would generally be that of the primary of the bridging transformer, $T_{d}$. Ground currents may be at power line frequencies or at the test frequency. The former are usually easy to identify while those at the test frequency may be difficult to detect. Dealing effectively with either is more often than not difficult. The use of a coaxial choke 
in the detector branch is generally sufficient to minimize any ground currents. [28,29,30] When dealing with ground loop currents, no universal rule of "fix" can be stated since the ground circuit and current paths will vary from one setup to the next.

Several precautions must be observed when mounting the masses on the vibration table. These are important bearing in mind that the change of impedance for adding masses is small, and the fact that the desired solution is almost wholly dependent on how well the impedance change can be determined. It has been observed that the drive coil will show a change of impedance if the mean position is shifted. The causes have not been fully investigated but the effect has been noted. Therefore, when the masses are mounted on the table, assurances must be made that the armature occupies the same mean position in the magnetic gap. If the armature is arranged vertically, it will be at a lower position as the masses are increased. Provision has to be made to reposition the armature to its former position prior to making meaningful impedance measurements. This is, at best, difficult to accomplish. A better choice is to arrange the vibration exciter such that the armature is horizontal. When mass is then mounted, little if any lateral position shift occurs. The shifts, at any rate, are greatly reduced.

It has also been observed that the flexures on some vibration generators have an undesirable hysteresis. During the process of removing one mass and mounting another, it is impossible not to disturb the mean position of the armature. Once disturbed, it must return to within some small order of position. It was found that if the armature were gently tapped with a wooden pencil (the eraser end) while being vibrated, the armature would tend to overcome the hysteresis and return to its original position.

For most electrodynamic exciters of the type used for calibration purposes, the magnetic pole pieces are sufficiently open and unshielded such that magnetic shunting can occur in the vicinity of the exciter. It was found, for example, that screw drivers, allen wrenches, or other small magnetic articles can have a measurable effect on the drive-coil impedance when near the exciter.

Further, it is essential that the masses be made from nonmagnetic material and that the mounting screw or other attachment means be nonmagnetic. It was also observed that certain bridging transformers used in the detector branch would pick up extraneous stray fields owing to their open E-core type of construction. This either caused a noise or an error in the bridge null. 
The sensitivity factors, as calculated from eqs. 16, 17 and 18, are complex due to the complex values of the impedances and voltage ratios. The impedance difference, $\mathrm{Z}_{\mathrm{ca}}, \mathrm{Z}_{\mathrm{ba}}$ and $\mathrm{Z}_{\mathrm{cb}}$ are most easily calculated in rectangular form from eq. 19. Once the impedance differences are known, then the radical involving the impedance difference is best evaluated in polar form, that is, in terms of magnitude and phase angle. Also, the voltage ratio term can be used in polar form. The resulting sensitivity factors are then expressed in terms of a magnitude and phase angle. In many cases, the magnitude is all that is desired. If so, the phase angle measurement of the voltage ratio and subsequent calculations of the phase angles may be omitted. For most high quality accelerometers that have small amounts of damping, the phase shift is nearly zero at most of the frequencies of intended use. At very low frequencies, phase shift is often the result of the particular electronic amplifier used with the accelerometer. The phase angle at high frequencies does not change significantly until the pickup's resonance is approached.

\section{SENSITIVITY MEASUREMENT RESULTS}

\subsection{Measurement Preparation and Precautions}

A calibration type electrodynamic vibration exciter [31] with a built-in, high-quality piezoelectric accelerometer was calibrated by the Three-Mass reciprocity method. The exciter was selected because of its light moving element which is made of beryllium. It was operated in a horizontal position to minimize armature shift when masses were mounted.

A small thermocouple was attached to the table surface. The purpose was to determine when temperature equilibrium was achieved. It was necessary to operate the exciter for a one-to-two day period with a constant current, $I_{\ell}$, so that the operating temperature could be reached. A slow air flow was supplied to help cool the armature drive coil. The masses were stowed on a heated surface a few degrees warmer than the room temperature and approximately the same temperature as the exciter table. Insulation was placed over them to minimize a thermal gradient while in the stowed condition.

The mass values selected were

$$
\begin{aligned}
& \mathrm{M}_{\mathrm{a}}=0, \\
& \mathrm{M}_{\mathrm{b}}=45.18 \text { grams, and } \\
& \mathrm{M}_{\mathrm{c}}=135.18 \text { grams. }
\end{aligned}
$$


The selection of $\mathrm{M}_{\mathrm{a}}=0$ simplifies the sensitivity calculations from eqs. 16, 17 and 18 and eliminates one source of error, namely that of the measurement of the mass $M_{a}$; zero mass can be precisely defined. Mass $M_{b}$ was selected to be about one-third the mass $M_{c}$.

When mounting the masses on the exciter, it was necessary to maintain the drive-coil current at a constant value for temperature stability considerations. As such, the table had to be in motion when the masses were being mounted. With some practice, this was not too difficult at the higher frequencies where the vibratory displacement was small.

Care was exercised in handling the masses during mounting. Thermally insulated gloves were used to handle them. If direct hand contact was made, extra time would be required to wait for the thermal shock to dissipate. Temperature changes of the drive coil in excess of 0.040 to $0.060{ }^{\circ} \mathrm{C}$ produces significant errors in the Three-Mass reciprocity measurement. Acceptable data results when the drive-coil temperature remains constant to with about $\pm 0.015{ }^{\circ} \mathrm{C}$. It is not critical as to the exact value of temperature so long as the temperature does not change while measuring $\mathrm{Z}_{\mathrm{a}}, \mathrm{Z}_{\mathrm{b}}$ and $\mathrm{Z}_{\mathrm{c}}$.

Best results were obtained when the test mass sequence was in the order $M_{a}-M_{b}-M_{c}-M_{b}-M_{a}$. The value of $Z_{a}$ was averaged from the two readings for mass $M_{a}$, and $Z_{b}$ was averaged from the two readings for mass $M_{b}$. Slight thermal drifts were then compensated for by this process.

\subsection{Measurement Analysis}

6.2.1 Input Data: Figures $6 \mathrm{a}, 6 \mathrm{~b}$, and $6 \mathrm{c}$ show the computer printout of typical measurements at $1000 \mathrm{~Hz}$. The BASIC language program for this printout is given in the appendix.

The program name (R3MSI2 - R, Reciprocity; 3MS, 3 Mass; I, current sensing; 2, version number), date (3/9/70) and test number (365010, etc.) are given at the top of the printout.

The next two lines are the ratio transformer readings ( $K(1), K(2)$ and $K(3)$ ) and capacitor readings ( $(1), C(2), C(3))$ for the bridge configuration as shown in figure 4 . The readings 1,2 and 3 correspond to mass loads $\mathrm{M}_{a}, \mathrm{M}_{\mathrm{b}}$ and $\mathrm{M}_{\mathrm{c}}$ which are mounted in the table. The ratio transformer reading will always be between zero and unity. The value of capacitance is entered in microfarads. 
The next block of information are voltage and phase measurements. $\mathrm{V}(1,1), \mathrm{V}(1,2)$ and $\mathrm{V}(1,3)$ are the output voltage, $\mathrm{E}^{\mathrm{P}}$, of the accelerometer pickup and its accompanying charge amplifier for the three masses. (V2,1), $\mathrm{V}(2,2)$ and $\mathrm{V}(2,3)$ are the voltage drops, $E^{S}$, measured across the fourterminal resistor, $R_{S}$, and is proportional to the armature current. $Q(2,1), Q(2,2)$ and $Q(2,3)$ are phase angles of the two voltages, $E^{P}$ referenced to $\mathrm{E}^{\mathrm{S}}$, in degrees. The voltages must be expressed in millivolts (as shown here). Phase measurements were not made and the nominal value of zero degrees was used in all the computations.

The next line gives the frequency (f) in hertz, and the value of $R_{s}\left(R_{1}\right)$ in ohms.

6.2.2. Computed Values: The following blocks of computed results are correspondingly identified in figures $6 a, 6 b$, and $6 c$.

$\underline{\mathrm{Y}}$

$\underline{R(Y)}$

$\underline{X(Y)}$

MAG Z(Y)

$Q(Y)$

Y DIFF

$\underline{R(Y) D I F F}$

$\underline{X(Y) D I F F}$

Z(Y) DIFF

Q(Y) DIFF

MASS

SENS, MV/G
Mass number, $1=M_{a}, 2=M_{b}, 3=M_{c}$.

Value of resistive portion of drive-coil impedance in ohms; solved from eq. 19 or 21 , real part.

Value of reactive portion of drive-coil impedance in ohms; solved from eq. 19 or 21, imaginary part.

Magnitude of the drive-coil impedance in ohms; square root of the sum-of-the-squares of $R(Y)$ and $X(Y)$ above.

Impedance phase angle in degrees; solved from eq. 20 or 22 .

Mass differences, $(1-2)=\mathrm{M}_{\mathrm{ab}},(2-3)=\mathrm{M}_{\mathrm{bc}},(3-1)=\mathrm{M}_{\mathrm{ca}}$.

Resistance change (or difference) of drive-coil impedance for the indicated change of mass.

Reactance change of drive-coil impedance for indicated change of mass.

Impedance change of drive-coil impedance for indicated change of mass; $\mathrm{Z}_{\mathrm{ab}}, \mathrm{Z}_{\mathrm{bc}}$, and $\mathrm{Z}_{\mathrm{ca}}$.

Difference of phase angles for impedance changes for indicated mass change.

Value in grams of masses; $\mathrm{M}_{\mathrm{a}}=0, \mathrm{M}_{\mathrm{b}}=45.18, \mathrm{M}_{\mathrm{c}}=135.18$ System sensitivity (including amplifier) of pickup being calibrated. 
PHASE

ACCEL, G'S

VOLT RATIO

NOM SENS

AVE SENS

DEV FRM NOM

MASS, TOTAL

DEV FM AVE

DEV FM NOM

MASS RAD

IMPED RAD
Phase angle, in degrees, of the sensitivity factor. rms test acceleration.

Ratio of $\left(E^{\mathrm{P}} / \mathrm{E}^{\mathrm{S}}\right)$.

Nominal system sensitivity, $\mathrm{S}^{\mathrm{P}}$, in $\mathrm{mV} / \mathrm{g}$.

Average system sensitivity of $\mathrm{s}_{\mathrm{a}}^{\mathrm{P}}, \mathrm{s}_{\mathrm{b}}^{\mathrm{p}}$, and $\mathrm{s}_{\mathrm{c}}^{\mathrm{P}}$, in $\mathrm{mV} / \mathrm{g}$.

Percent deviation of system sensitivity, $\mathrm{S}^{\mathrm{P}}$, from the nominal value.

Computed effective mass in grams of armature plus load mass.

Percent deviation from average for each value of $\mathrm{s}^{\mathrm{p}}$. Percent deviation from nominal for each value of $\mathrm{s}^{\mathrm{p}}$. The value of the mass radicals of eqs. 16,17 and 18 . The value of the impedance radicals of eqs. 16, 17 and 18.

As can be seen from the data in figures $6 a, 6 b$, or $6 c$, the resistive portion of the drive-coil impedance is approximately 7 ohms and the reactance is about 4 ohms. The total impedance vector is about 8 ohms. The Three-Mass reciprocity solution makes use of the impedance difference. $(\mathrm{Z}(\mathrm{Y}) \mathrm{DIFF})$ which is in the order of 0.04 to $0.08 \mathrm{ohms}$. It is this impedance difference that must be determined accurately. These values appear directly in eqs. 16, 17 and 18 for the solution of the pickup sensitivity.

The system sensitivity (including a charge amplifier) was about $10 \mathrm{mV} / \mathrm{g}$. For example, in figure $6 a$,

$$
\begin{gathered}
\mathrm{S}_{\mathrm{a}}^{\mathrm{p}}=10.0837 \mathrm{mV} / \mathrm{g}, \\
\mathrm{S}_{\mathrm{b}}^{\mathrm{P}}=10.0687 \mathrm{mV} / \mathrm{g}, \\
\mathrm{S}_{\mathrm{C}}^{\mathrm{P}}=10.032 \mathrm{mV} / \mathrm{g}, \text { and } \\
\text { Average }=10.0615 \mathrm{mV} / \mathrm{g}, \text { rounded to } 10.06 \mathrm{mV} / \mathrm{g} .
\end{gathered}
$$

The maximum difference between readings was about 0.5 percent for this example. It is mainly due to thermal drifts and slight repositioning errors of the armature. 
For the data selected as examples, the averages were as follows:

$$
\begin{aligned}
\text { Average sensitivity for test } 365010 & =10.06 \mathrm{mV} / \mathrm{g}, \\
\text { Average sensitivity for test } 365020 & =10.06 \mathrm{mV} / \mathrm{g}, \\
\text { Average sensitivity for test } 365030 & =10.07 \mathrm{mV} / \mathrm{g}, \\
\text { Mean of the above averages } & =10.06 \mathrm{mV} / \mathrm{g} .
\end{aligned}
$$

The last underscored digit above indicates rounded data to nearest onetenth percent.

Table I shows the results of Three-Mass reciprocity calibration at two frequencies, 600 and $1000 \mathrm{~Hz}$. Repeated measurements were made and at $1000 \mathrm{~Hz}$, two different observers made the measurements. The amplifier gain was divided out of the system sensitivity so that all the values given are in terms of accelerometers sensitivity in units of picocoulombs per unit acceleration in $\mathrm{g}(\mathrm{pC} / \mathrm{g})$. Within each group, the sensitivity is given for each mass load, $\mathrm{M}_{a}, \mathrm{M}_{b}$, or $\mathrm{M}_{c}$, as well as the group means. A grand mean is given at the bottom of the table for the 38 tests at $1000 \mathrm{~Hz}$.

The standard deviations shown never exceeded about \pm 0.4 percent and were quite often only \pm 0.1 or \pm 0.2 percent. In all instances, the standard deviations for mass $M_{c}$ was higher than with either $M_{a}$ or $M_{b}$. This is felt to be the result of the testing sequence of mounting the masses. As previously stated, a mass sequence of $M_{a}-M_{b}-M_{c}-M_{b}-M_{a}$ was employed. Calculations were based on the average of the two $Z_{a}$ and $Z_{b}$ measurements, but only a single measurement of $Z_{c}$ was made.

Another observation made is that within any one group, the data clusters together with a relatively small standard deviation. However, the differences between three $1000 \mathrm{~Hz}$ groups exceeds the standard deviations by several times. For example, the group II mean is +0.58 percent greater than the group III mean, and +1.16 percent greater than the group IV mean. This "day-to-day" shift is not totally explained, but thought to be related to temperature instabilities and the operator procedural technique. Accounting for the spread, the pooled standard deviation of the grand mean is about \pm 0.45 percent. Testing this value does indeed verify that about 64 percent of the 38 readings fall within the \pm 0.45 percent limits. 
6.2.3. Estimate of Measurement Errors: The following estimate of errors was made for the impedance measuring bridge circuit shown by figure 4 at a frequency of $1000 \mathrm{~Hz}$. Equations 16, 17, 18 and 19 were used as a basis for the error analysis.

6.2.3.1 Constant, 123.718: This constant was derived following eq. 13 . The error in this value is controlled by the estimate of the value for $\pi$. The value used was $\pi=3.14159$, rounded to six digits from 3.1415927 resulting in an approximate 3 parts in $3 \times 10^{5}$, or -0.001 percent error. The standard gravity value used was $1 \mathrm{~g}=9.80665 \mathrm{~m} / \mathrm{s}^{2}$, as defined. The final value of 123.718 was rounded from 123.7178 , resulting in an approximate +2 parts in $1.2 \times 10^{6}$, or +0.00017 percent error. Adding these two sources of error combining in the worst case is about \pm 0.0012 percent.

6.2.3.2 Frequency Radical: At a nominal frequency of $1000 \mathrm{~Hz}$, it was measured to within $\pm 0.1 \mathrm{~Hz}$ or an error of \pm 0.01 percent. This effects the results to less than half or \pm 0.005 percent.

6.2.3.3 Mass Radical: For the values of mass used, the measurement error was \pm 5 milligrams.

$$
\begin{aligned}
& M_{a}=0 \text { grams, } \pm 0 \text { grams, } \pm 0 \text { percent error, } \\
& M_{b}=45.18 \text { grams, } \pm 0.005 \text { grams, } \pm 0.011 \text { percent error, } \\
& M_{c}=135.18 \text { grams, } \pm 0.005 \text { grams, } \pm 0.0037 \text { percent error. }
\end{aligned}
$$

The solution for sensitivity uses mass differences. Combining the above errors, the estimated uncertainty of $\mathrm{M}_{\text {ba }}$ is \pm 0.011 percent, of $\mathrm{M}_{\mathrm{ca}}$ is \pm 0.0037 percent, and of $\mathrm{M}_{\mathrm{cb}}$ is \pm 0.0148 percent. Combining these in a worst case condition, the mass radical could have an uncertainty of

$$
1 / 2( \pm 0.011 \pm 0.0037 \pm 0.0148) \approx \pm 0.015 \text { percent }
$$

6.2.3.4 Impedance Radical: The evaluation of this error is difficult because of the possible ways in which measurement errors can combine. Notwithstanding, the controlling parameter for the impedance differences is the capacitance determinations. These were measured to within $\pm(0.5$ percent of the value $\pm 50 \mathrm{pf})$ for each reading, the $\pm 50 \mathrm{pf}$ being the resolution of the capacitor readings. This results in a \pm 5 parts in about $3.7 \times 10^{5}$ or \pm 0.0014 percent resolution. The \pm 0.5 percent value completely overwhelms the resolution. 
The errors in the ratio transformer setting combine to be approximately the percentage uncertainty of the resolution used, or \pm 5 parts in $3.6 \times 10^{5}$ or \pm 0.0014 percent. The ratio transformer causes errors only in the resistive part of the impedance measurement. In addition, errors in the value of $R_{s}$ directly effect the measurement of the resistive portion of drive-coil impedance. The uncertainty in $R_{s}$ was estimated as \pm 0.1 percent. This error overrides errors in the ratio trănsformer.

Combining the errors involved in the resistive and reactive portions of the impedance, a fair estimate of the uncertainty of measurement of the impedance is \pm 0.51 percent.

In evaluating the impedance radical uncertainty, frequency is involved in the reactive terms. However, as long as the frequency is constant during the course of measuring, the exact frequency is of little consequence. It effectively divides out with the frequency term previously discussed in section 6.2.3.2. The overall estimated uncertainty in the impedance radical term is \pm 0.75 percent.

6.2.3.5 Standard Four-Terminal Resistance: The ac resistance of $\mathrm{R}_{\mathrm{s}}$ was known to within \pm 0.1 percent at all values of current that were used.

6.2.3.6 Voltage Ratio: Two separate voltmeters were used to measure the voltages, $E^{\mathrm{P}}$ and $E^{\mathrm{S}}$. Their individual uncertainties were $\pm(0.1$ percent of input $+25 \mu \mathrm{V})$ for one and $\pm(0.05$ percent of input +0.005 percent of range) for the other. For typical ranges and voltages encountered, the worst case uncertainty was less than \pm 0.17 percent.

6.2.3.7 Combined Total Uncertainty: Listed below are the major identifiable sources of uncertainty for the Three-Mass reciprocity measurements and using the circuit shown in figure 4.
a. Physical constants
b. Frequency
c. Mass Radical
d. Impedance Radical
e. Four-terminal Resistance
f. Voltage ratio
g. Distortion, stability, etc.
h. Unexplained Effects

0.001 percent

0.005 percent

0.015 percent

0.75 percent

0.10 percent

0.17 percent

0.25 percent

1.00 percent 
Worst Case Summation Uncertainty $= \pm 2.291$ percent, rounded to \pm 2.3 percent.

Root-sum-square Uncertainty $= \pm 1.290$ percent, rounded to \pm 1.3 percent.

The measured data all fall well within these uncertainty limits. The largest sources are the impedance difference measurements, voltage ratio measurements and the thermal stability of the process. To ensure a conservative uncertainty statement, a miscellaneous \pm 1 percent was included for operator procedural differences and other effects that are not well evaluated.

Known improvements could be made to decrease the uncertainty of the impedance radial error from \pm 0.75 to \pm 0.075 percent, the four-terminal resistance error for \pm 0.1 to \pm 0.05 percent, the voltage ratio error from \pm 0.17 to \pm 0.1 percent, the distortion and stability errors from \pm 0.25 to \pm 0.1 percent, and the unexplained effects from \pm 1 to \pm 0.1 percent. The ultimate uncertainties might then be as small as about \pm 0.5 percent worst case and \pm 0.2 percent for the root-sum-square case.

If the bridge circuit as shown in figure 5 were used, similar uncertainties would exist, although some of the sources of error would be different from those discussed above.

\section{OTHER RECIPROCITY METHODS INTERCOMPARISONS}

\subsection{Three-Mass and Bouche-Levy Reciprocity Methods}

A series of "back-to-back" transfer comparisons were made between the built-in standard accelerometer discussed herein and two other electrodynamic exciters calibrated by the Bouche-Levy reciprocity method [1], 12,13,14]. The total uncertainty of the intercomparisons becomes the sum of the errors of the original Bouche-Levy reciprocity calibration, transferring from those standards to a transfer standard accelerometer, and then transferring from this accelerometer into the ThreeMass reciprocity calibrated standard.

The total uncertainty of transferring a value from the Bouche-Levy calibrated standards did not exceed \pm 1 percent. Transferring this into the Three-Mass calibrated standard accumulated about an additional \pm 0.25 percent. Thus the total intercomparison uncertainty should agree to within about $( \pm 1.25$ percent $)+( \pm 1.3$ percent $)= \pm 2.55$ percent, the sum of the two uncertainties. 
Figure 7 shows the results of the Three-Mass reciprocity calibration, the Bouche-Levy intercomparison, and the manufacturer's value. The circles are the Three-Mass measured values for each of the the three masses. Generally, $\mathrm{S}_{\mathrm{a}}^{\mathrm{p}}$ and $\mathrm{s}_{\mathrm{c}}^{\mathrm{p}}$ are grouped together while $\mathrm{s}_{\mathrm{b}}^{\mathrm{p}}$ tends to assume a slightly different value. This is a result of the sequence in which the laboratory measurements are made. Masses $M_{a}$ and $M_{c}$ are used twice while mass $M_{b}$ is used only once. Certain thermal drifts tend to cancel out for $S^{\mathrm{P}}$ and $\mathrm{S}^{\mathrm{P}}$. The "diamond" shaped sympols are weighted mean values. The solid lines extending from the Three-Mass reciprocity data indicate the $\pm 1 \sigma$ standard deviations for the respective data. The dashed lines indicate the overall estimated uncertainty for each value. All three mean values agreed with one another to within about 1 percent. The Three-Mass weighted grand mean value was about 0.65 percent greater than Bouche-Levy value and about 0.40 percent lower than the manufacturer's value.

\subsection{Power-Balance and Bouche-Levy Methods}

The theory used to develop the Power-Balance reciprocity method [20] uses the same set of measurements as required for the Bouche-Levy method. For the Power Balance method, the drive-coil impedance was represented by the electrical parameters of the drive coil and by the dynamical quantities reflected as electrical impedances. The dynamic electrical resistance was attributed to mechanical friction and the radiation of sound (the latter certainly being very small). Uicker divided the power into two types; 1) that lost and nonrecoverable due to mechanical friction, Joule heating, etc., in the resistive elements of the circuit, and 2) that power which is stored in the reactances of the circuit and recovered during each complete vibration cycle. The theory then assumes that all of the "reactive power" produced by the back emf must balance the time-rate-of-change of the kinetic energy in the moving elements (hence this method's name, Power-Balance). This is a statement of the law of conservation of energy.

When making the necessary measurements, the open circuit voltage ratio of the drive coil to signal generator is measured. This is accomplished by driving the vibration exciter mechanically by a second and independent mechanical vibration source. Because this is an open circuit measurement, the drive-coil current is zero. When making the transfer admittance measurements, the drive coil carries the current which in turn produces the vibratory motion. This alternating current in the drive coil causes an induced current to flow in the pole pieces of the magnetic structure of the exciter. These eddy currents dissipate power through Joule heating as a function of the volume resistivity of the pole pieces. Additionally, there is a component of inductance associated with the eddy current flow. This reflects as a reactive component back into the drive coil impedance. 
The Power-Balance theory does not consider the eddy current effects when the "reaction power" is equated to the time-rate-of-change of the kinetic energy. The kinetic energy is a totally reactive quantity. The "reactive power" should be totally reactive, but contains a real, inphase component because of the eddy current losses.

Comparative analyses of identical laboratory data by both the PowerBalance and Bouche-Levy methods shows an increasing discrepancy of results at higher frequencies. At frequencies up to about $2 \mathrm{kHz}$ there was acceptable agreement to within \pm 1 percent. Above $2 \mathrm{kHz}$, the Power-Balance method gave significantly higher values than the Bouche-Levy method. Eddy current losses are known to increase with increasing frequency for vibration exciters. This is, of course, different for each design and type of exciter. As such, the Power-Balance method may work to higher frequencies using some other exciter, or conversely, it may not work to as high a frequency.

No attempt was made to modify the Power-Balance theory to account for the eddy current losses and reactances although this should be possible. It would no doubt complicate the theory and possibly require additional laboratory measurements in the process.

\section{CONCLUSIONS}

The Three-Mass reciprocity theory was developed and experimental values of sensitivity factors were obtained for an accelerometer mounted within an electrodynamic vibration exciter. The Three-Mass reciprocity method requires that the electrical impedance of the drive coil be measured while each of three masses are mounted on the exciter table. The sensitivitv solution is then in terms of mass change, dectrica impedance change, voltage ratio, the value of a four-terminal resistor and frequency. The effects of frequency are second order and no precise determination is necessary.

Figure 7 compares the results of the Three-Mass reciprocity calibration with the Bouche-Levy reciprocity calibration and the manufacturer's value. The weighted grand mean value for the Three-Mass method is within approximately \pm 0.5 percent of both the Bouche-Levy value and the manufacturer's value.

The advantages of the Three-Mass reciprocity method are:

1. Only one linear, reciprocal and bilateral transducer is required. A good quality electrodynamic vibration exciter having a single drive coil meets this requirement. For convenience and improved stability, the calibration of the drive coil is transferred to a piezoelectric accelerometer mounted in the armature. 
2. There is no necessity of driving one exciter by a second one, such as is the case with the Bouche-Levy and Power-Balance reciprocity methods. This eliminates the ailgnment problems.

3. The calibration is principally a function of the measurement of the change of drive-coil impedance for a change of mass added to the armature. This measurement can be made in a short period of time thus minimizing changes with time. With care, these measurements can be made precisely.

Two difficulties of the Three-Mass method are: 1) the impedance change is small for a relatively large change of armature mass, and 2) the impedance difference is extremely temperature sensitive. In order to be successful, temperature monitoring and control are necessary. The drive-coil temperature must remain constant to within about $\pm 0.015{ }^{\circ} \mathrm{C}$. Further development of the method should be in the direction of temperature control. This would speed the measurement process and improve the quality of the results.

\section{ACKNOWLEDGEMENTS}

The Three-Mass reciprocity theory was originally proposed and derived by Seymour Edelman. Many helpful discussions were held with personnel of the Electricity Division of NBS, particularly Mr. Robert Cutkosky regarding ratio transformer bridges. In this same regard, Mr. E. A. Anderson of the Metrology Engineering Center, Pomona also made helpful suggestions. Mr. B. F. Payne contributed ideas from his experiences with the Bouche-Levy method and also performed work using the Power-Balance method. Mr. W. E. Epstein acted as a second observer to collect laboratory data and also assisted in the error analysis. 


\section{REFERENCES}

1. Trent, H. M., "The Absolute Calibration of Electromechanical Pickups", J. Applied Mechanics, Vol. 15, No. 1, Mar. 1948.

2. Cook, R. K., "Absolute Pressure Calibrations of Microphones", J. Research NBS, Vo1. 25, (1940) (RP1341).

3. London, A., "The Absolute Calibration of Vibration Pickups", NBS Tech. News Bulletin, Vol. 32, Jan. 1948.

4. Thompson, S. P., "Reciprocity Calibration of Primary Vibration Standards", NRL Report F-3337, Aug. 1948.

5. Thompson, S. P., "Reciprocity Calibration of Primary Vibration Standards", J. Acoustical Soc. Am., Vol. 20, No. 5, Sept. 1948.

6. Thompson, S. P., "Theoretical Aspects of the Reciprocity Calibration of Electromechanical Transducers", NRL Report F-3371, Oct. 1948.

7. Thompson, S. P., "The Reciprocity Calibration of Electromechanical Transducers", Doctoral Thesis Dissertation, Yale (1950).

8. Harrison, M., Sykes, A. O., Marcotte, P. G., "The Reciprocity Calibration of Piezoelectric Accelerometers", DTMB Report 811 , Mar. 1952.

9. Harrison, M., et al, "The Reciprocity Calibration of Piezoelectric Accelerometers", J. Acoustical Soc. Am., Vol. 24, No. 4 (1952).

10. Camm, J. C., "The Reciprocity Calibration of a Vibration Pickup Calibrator", NBS Report 2651 (1953).

11. Levy, S., Bouche, R. R., "Calibration of Vibration Pickups by the Reciprocity Method", J. Research NBS, Vol. 57, No. 4 (1956).

12. Bouche, R. R., "Development of Standards for the Measurement of Vibratory Motion", Doctoral Thesis Dissertation, Dept. of Mech. Engr., U. Maryland, Dec. 1958.

13. Bouche, R. R., Ensor, L. C., "Use of Reciprocity Calibrated Accelerometer Standards for Performing Routine Laboratory Comparison Calibrations", Shock and Vibration Bulletin, No. 34, Part 4, Feb. 1965. 
14. Payne, B. F., "Absolute Calibration of Vibration Generators with Time-Sharing Computer as Integral Part of System", Shock and Vibration Bulletin, No. 36, Part 6, Feb. 1967.

15. Schmidt, V. A., Edelman, S., Smith, E. R., Jones, E., "Optical Calibration of Vibration Pickups at Smal1 Amplitudes", J. Acoustical Soc. Am., Vo1. 33, No. 6, June 1961.

16. Schmidt, V. A., Edelman, S., Smith, E. R., Pierce, E. T., "Modulated Photoelectric Measurement of Vibration", J. Acoustical Soc. Am., Vol. 34, No. 4, Apr. 1962.

17. Sheeks, O. P., "Methods for the Practical Reciprocity Calibration of Piezoelectric Accelerometers", Instr. Soc. Am. Reprint 68-581 (Paper presented at the 1968 ISA Annual Conference, Oct. 1968, New York).

18. Private communication from S. Edelman to J. Ramboz, Oct. 1965. (This stated the original idea, theory, and developed the mathematical solution for the voltage sensitivity of an electrodynamic vibration exciter.)

19. Private communications from J. Ramboz to S. Edelman, Jan. 23, 1966 and Mar. 13, 1966. (Verified theory and discussed problems. Also preliminary measurements from electrodynamic vibration exciter.)

20. Uicker, J. J. Jr., Bain, F., "Absolute Calibration of Accelerometers by a Power Balance Technique", unpublished paper, U. S. Army Metrology and Calibration Center, Frankford Arsenal, Philadelphia, (era 1966).

21. Malloy, C. T., "Use of Four-Pole Parameters in Vibration Calculations", J. Acoustical Soc. Am., Vo1. 29, No. 7, July 1957.

22. Malloy, C. T., "Four Pole Parameters in Vibration Analysis", Colloquium on Mechanical Impedance Methods for Mechanical Vibration, ASME, Dec. 1958.

23. Safford, F. B., "Measurement of Four-Pole Parameters of Complex Structures", J. Engineering for Industry, Transactions of the ASME, Feb. 1962 .

24. Lamb, H., "On Reciprocal Theorems in Dynamics", Proc. London Math. Soc., Vo1. 19, No. 144, Jan. 1888. 
25. Dimoff, T., Payne, B. F., "Application of Air-Bearings to an Electrodynamic Vibration Standard", J. Research NBS, Vol. 67C (Engr. and Instr.), No. 4, Oct.-Dec. 1963.

26. Dimoff, T., "Electrodynamic Vibration Standard with a Ceramic Moving Element", J. Acoustical Soc. Am., Vol. 40, No. 3, (1966).

27. Ramboz, J. D., "A Link-Compensated Ratio Transformer Bridge",, Review of Scientific Instruments, Vol. 42, No. 4, Apr. 1971.

28. Homan, D. N., "Applications of Coaxial Chokes to A-C Bridge Circuits", J. Research NBS, Vol. 72C, No. 2, Apr.-June 1968.

29. Riley, J. C., "Co-axers - What They Are and How to Use Them", ISA Advances in Instru., Vo1. 24, Part 3, Paper No. 69-616, Oct. 1969.

30. Sze, W. C., "An Injection Method of Self-Calibration of Inductive Voltage Dividers", J. Research NBS, Vo1. 72C, No. 1, Jan.-Mar. 1968.

31. Bouche, R. R., "A Practical Application of Accelerometer Calibrations", Shock and Vibration Bulletin No. 41, Part 3, Dec. 1970. 


\section{APPENDIX}

The following computer program is written in SUPER BASIC and will process Three-Mass reciprocity calibration data as obtained from the circuit shown in figure 4. For examples of the printout, see figures $6 \mathrm{a}, 6 \mathrm{~b}$, and $6 \mathrm{c}$. An explanation of the printout is given in Section 6.2.2. Masses are in grams, capacitances are in microfarads, voltages are in millivolts, and phases are in degrees.

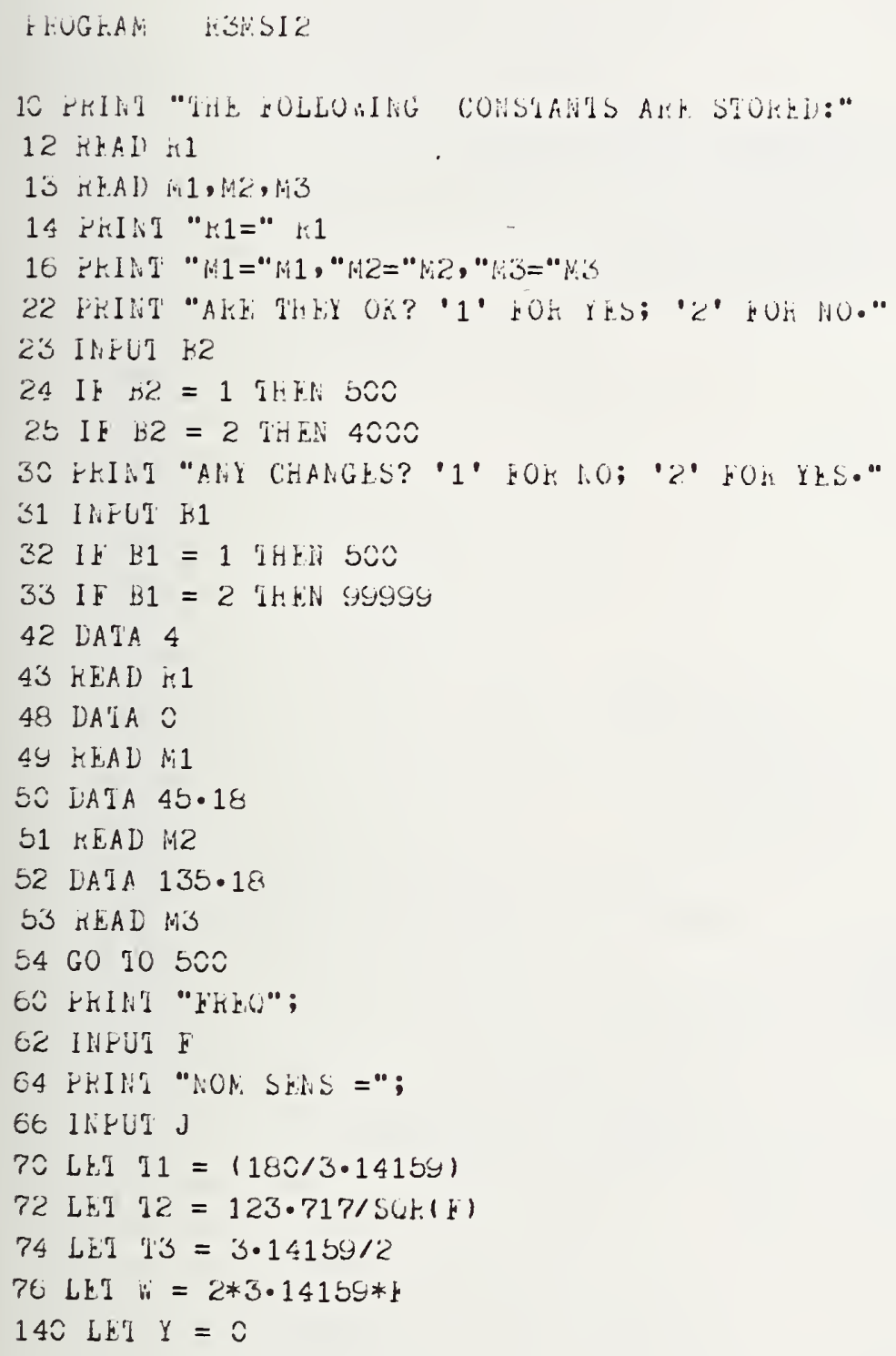




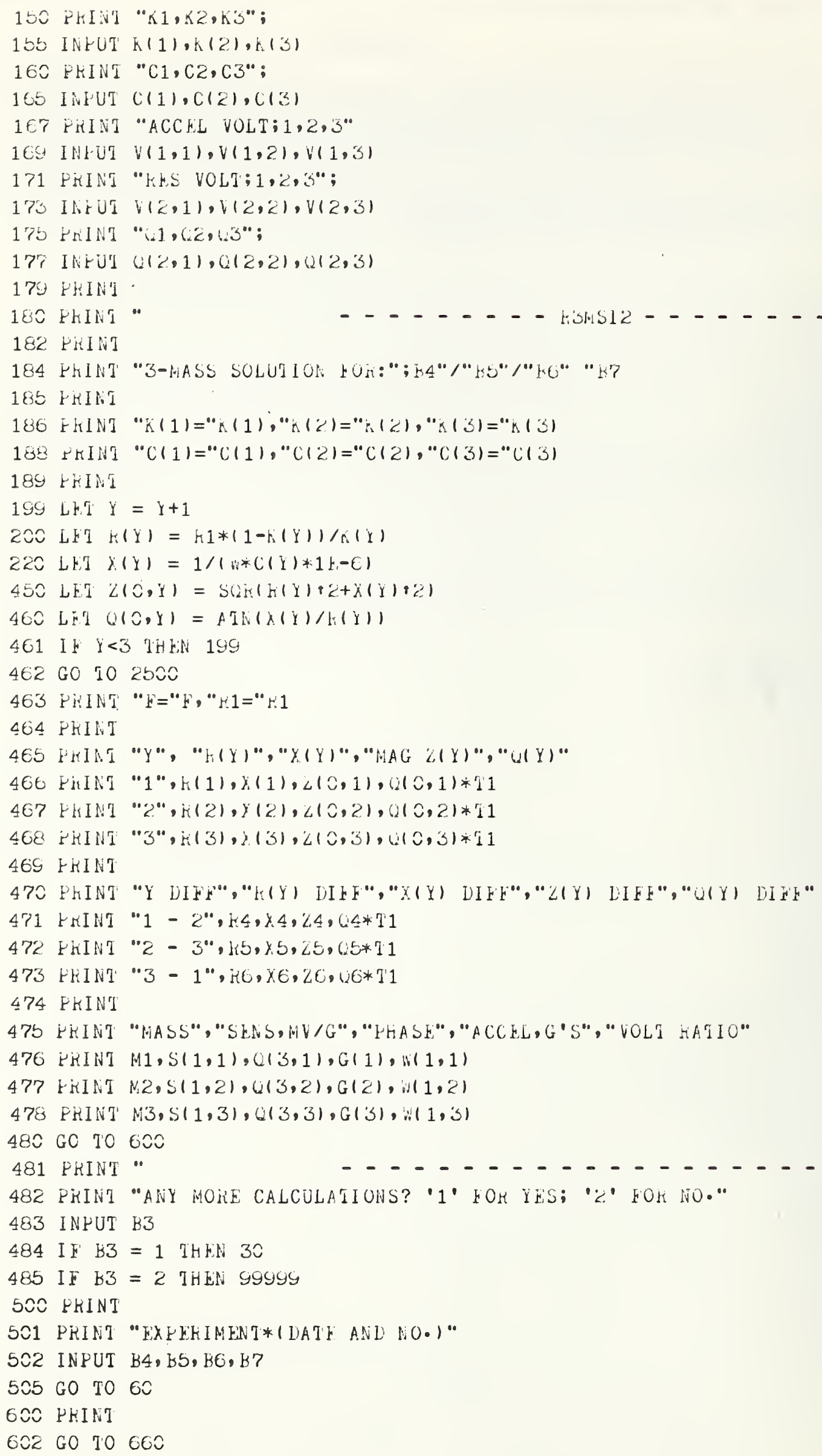




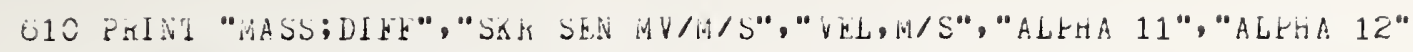
EZO Firlit $1: 1 ; " ; 1-2 ", b(2,1), V(9,1), A(1,1), A(2,1)$

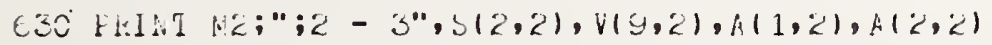

c40 fiLit lis;";1 - 3", S12,3), V(S,3),A(1,3), A(2, 3)

t.5O Print

cso Li. $H=(S(1,1)+S(1,2)+S(1,3)) / 3$

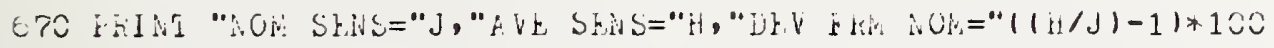

EBO FRIHT

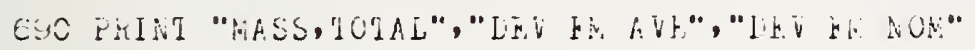

CS2 LEF $H 9=(13 * G(3)) /(G 11)-G(3))$

$6 y 4$ LEI HAS $=M Y y+M 2$

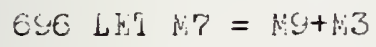

700 FHILI MS, $(1 S(1,1) / H)-1) * 100,(1 \leq(1,1) / J)-1) \times 100$

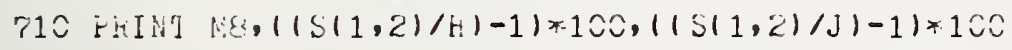

720 FKILI H?, (1S $(1,3) / H)-1) * 100,(1 S(1,3) / J)-1) * 100$

730 FKIIT

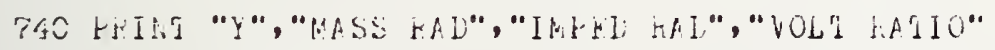

700 Hor $\mathrm{S}=1 \mathrm{TO} 3$

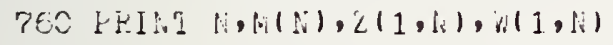

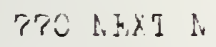

7yo GO 50481

2500 Lfi $K 4=\$(1)-\{(2)$

2510 Li'd $x 4=x(1)-x(2)$

2620 LkI $24=$ SUF $(k \leq 12+x 412)$

2530 LET $44=A I 1(x \leq / 44)$

2540 LET $k 5=k(2)-k(3)$

2550 LEI $\ddot{X} 5=x(2)-\pi(3)$

$2560 \mathrm{LET} L \mathrm{Lb}=\mathrm{S}(\mathrm{F}(\mathrm{KL}+2+\times 5+2)$

2570 LEI $\left.65=A^{\prime} 1 N(1) / 5 / \times 5\right)$

2580 Ll: $1: 6=1.131-1.11)$

2590 LET $X 0=x(3)-x(1)$

2EOS LWT $L E=\operatorname{SQn}(1,0 \cdot 2+x E+2)$

2010 LET C6 = ATH $(X E / \mathrm{KO})$

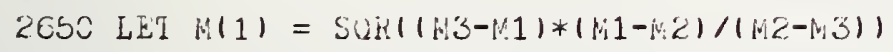

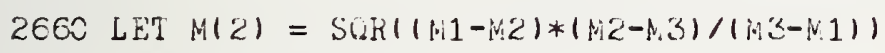

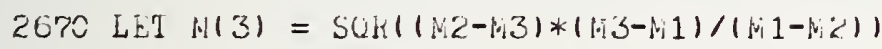

2680 LFI $Z 11,1)=\operatorname{SOr}(25 / 124 * 26) 1$

2690 LET $2(1,2)=S 6 F(26 /(Z 4 * 25))$

2700 LET $\angle(1,3)=\operatorname{S(KK}(24 /(\angle 5 * 26))$

2710 LET $(211,1)=(13+(2 b-04-(16) / 2$

2720 LET $(211,2)=113+(26-044-(25) / 2$

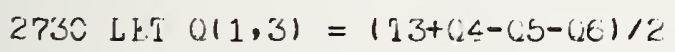

2731 GO $10 \quad 2750$

2735 LEI $A(1,1)=(S(2,1)-S(2,2)) / 1 ; *(1 ; 1-r i 2))$

2740 LEI $A(1,2)=(S(2,2)-S(2,3)) /(n+1)<-3) 1$

2745 LEI $A(1,3)=(S(2,1)-S(z, 3)) /\left(W *\left(N 1-N_{3} 3\right)\right)$

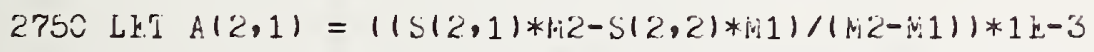

2755 LEI $A(2,2)=((S(2,2) *(j-S(2,5) * A 2) /(N S-1,2)) * 1 \mathrm{k}-3$

2780 LET $A(2,3)=(1 S(2,1) * M 3-S(2,3) * M 1) /(M-S 1) * 1 k-3$

2781 GO 103270 


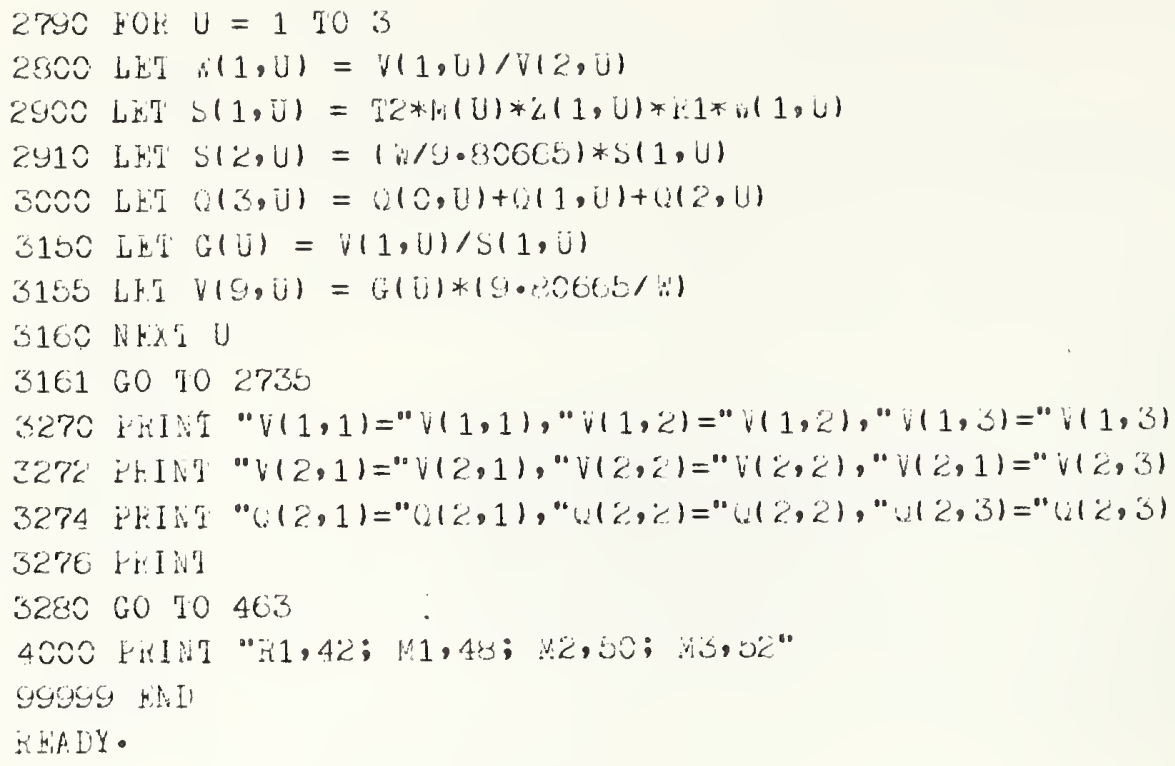


Table I. Three-Mass Reciprocity Calibration Results at 600 and $1000 \mathrm{~Hz}$.

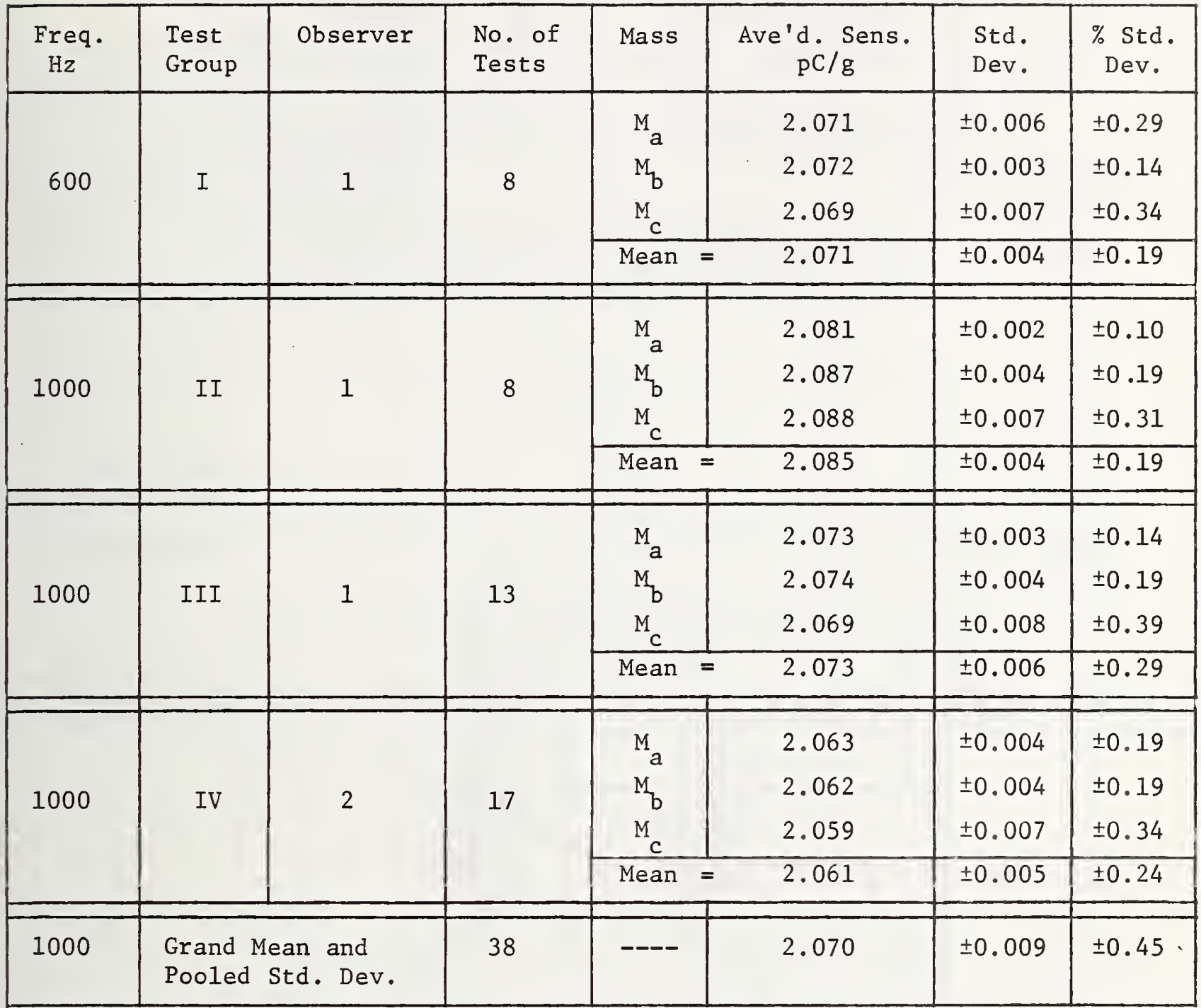




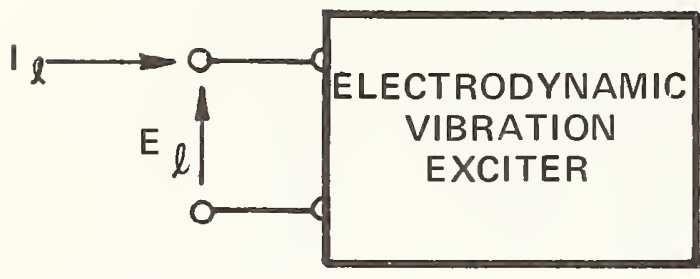

ELECTRICAL INPUT
PURE MASS

LOAD

$\mathrm{M}_{\ell}$

MECHANICAL OUTPUT

FIGURE 1. FOUR-POLE REPRESENTATION OF AN ELECTRODYNARIIC VIBRATION EXCITER WITH A PURE MASS LOAD.

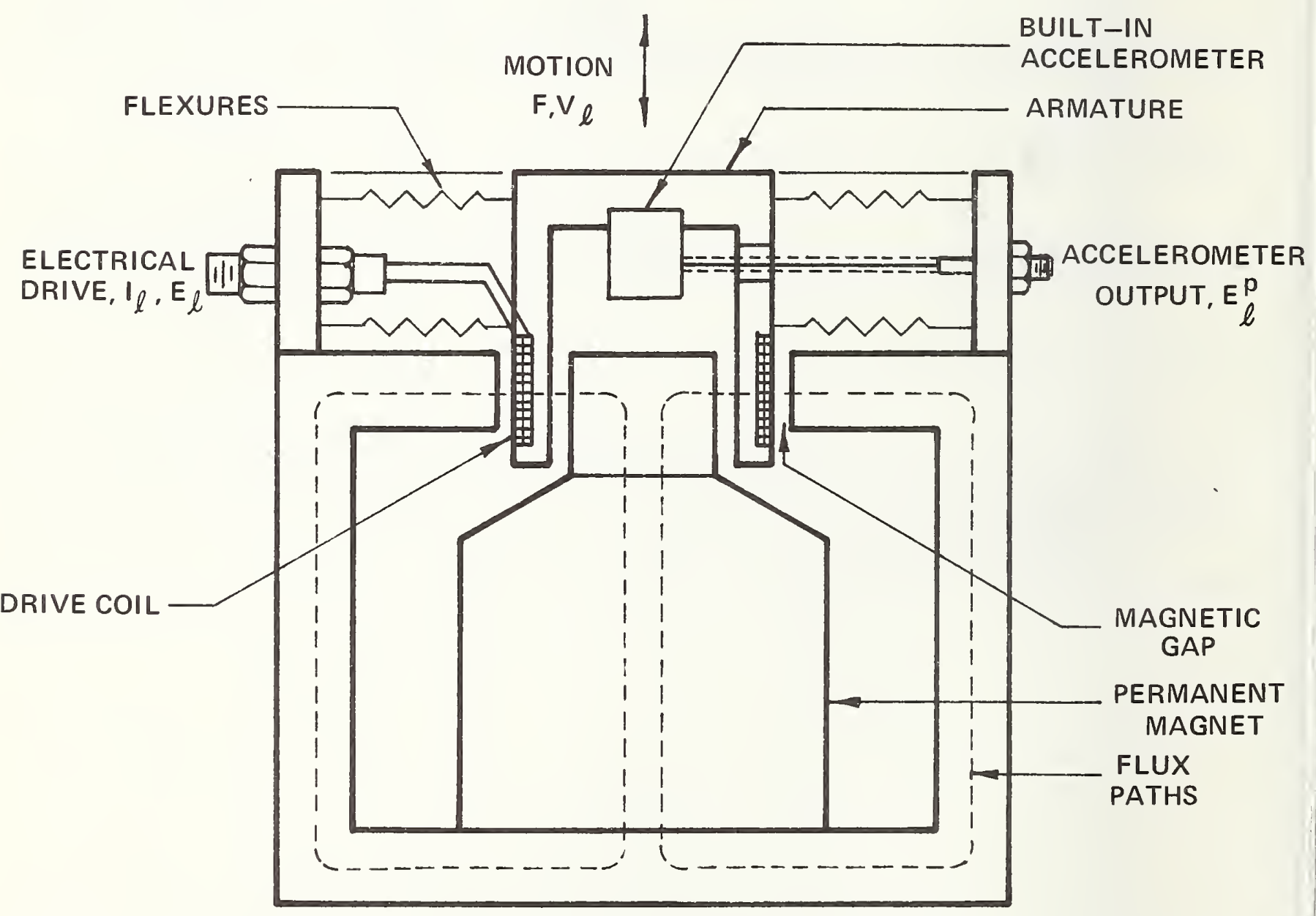

FIGURE 2. AN ELECTRODYNAMIC VIBRATION EXCITER WITH A BUILT-IN ACCELEROMETER. 


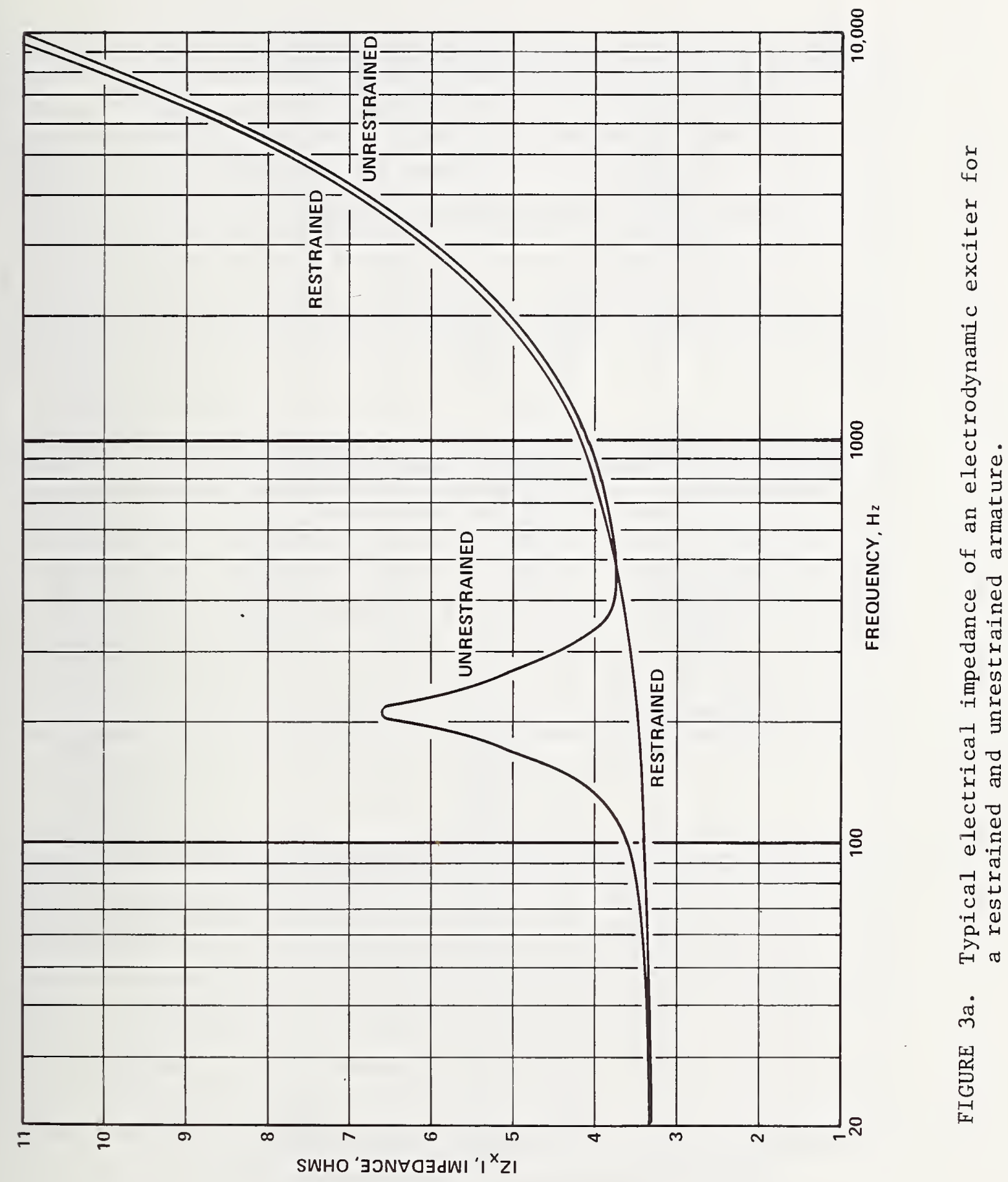



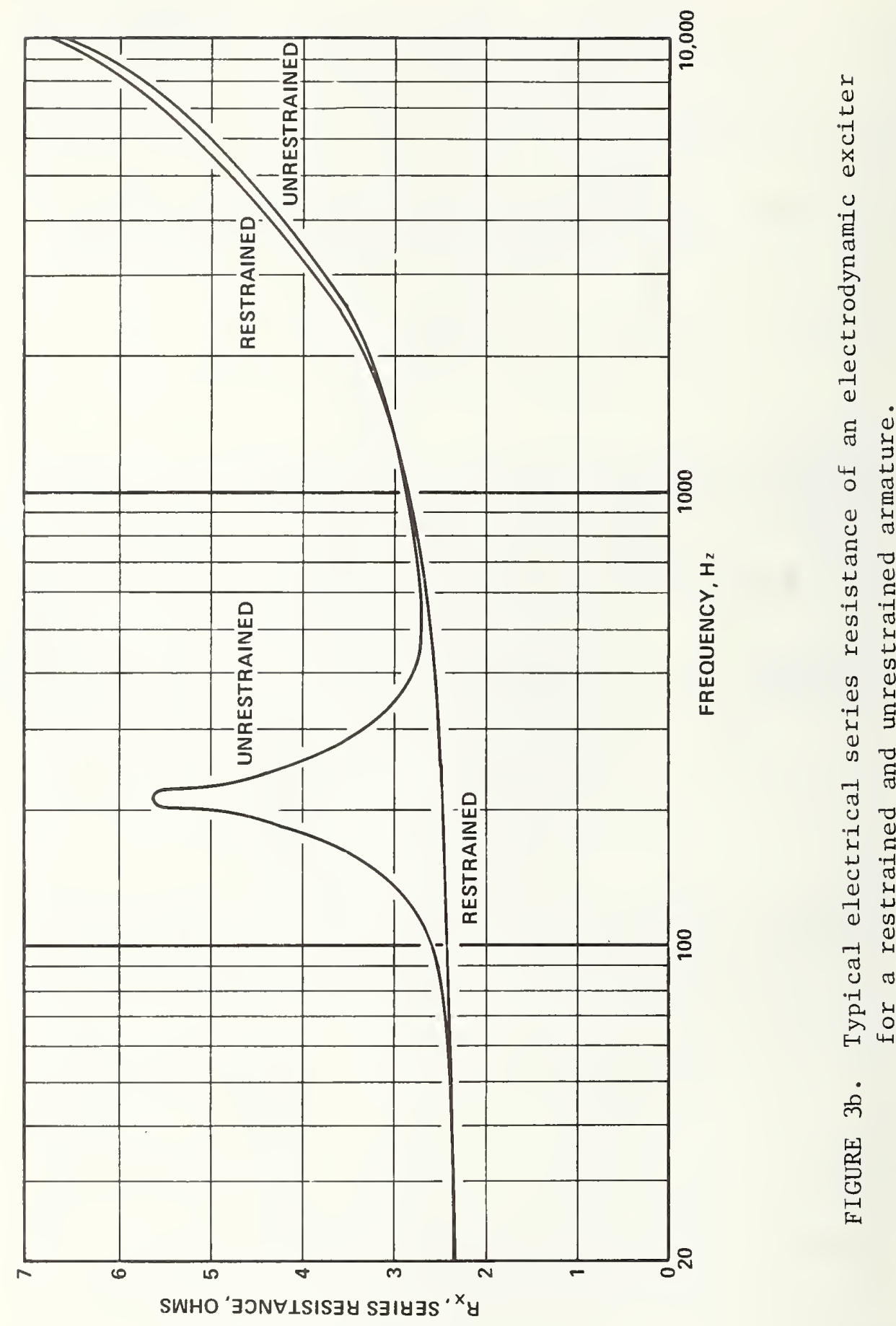


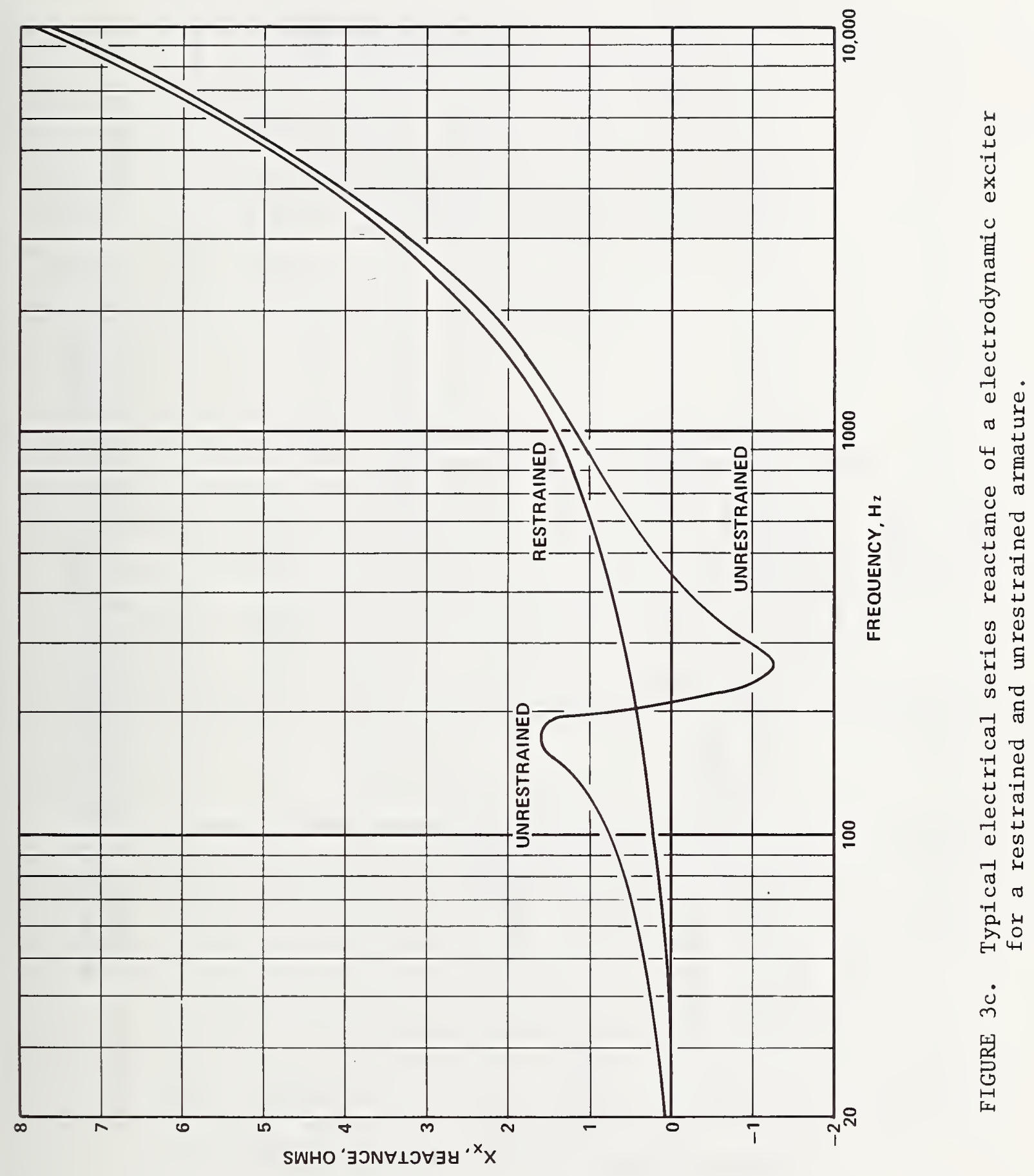




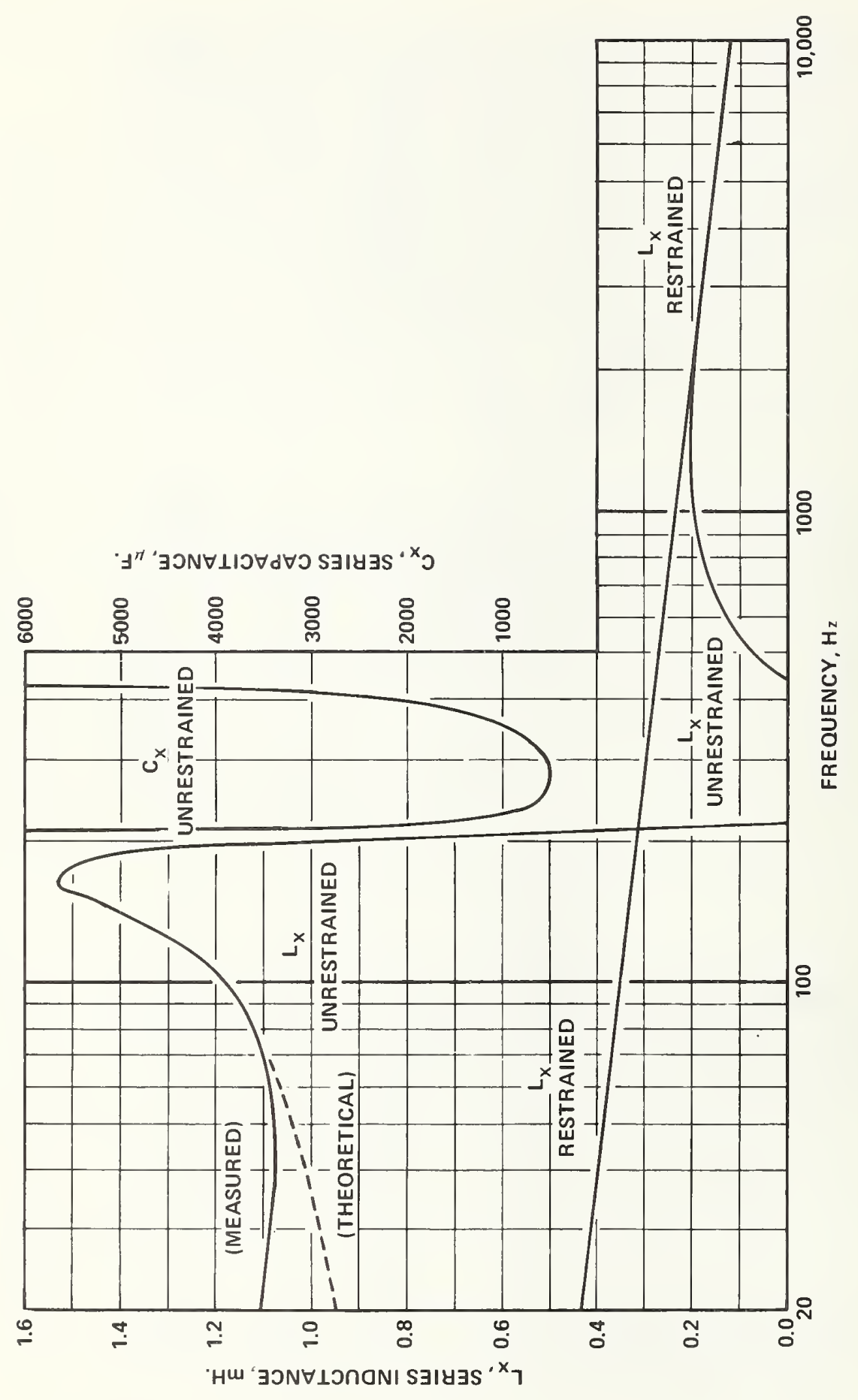

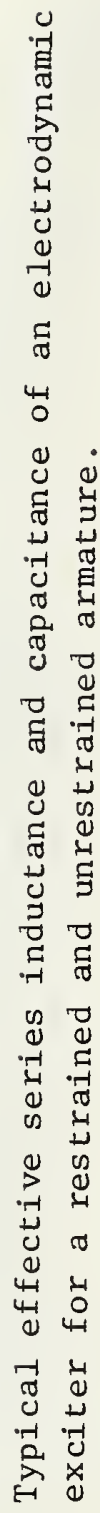

लं

䎋 

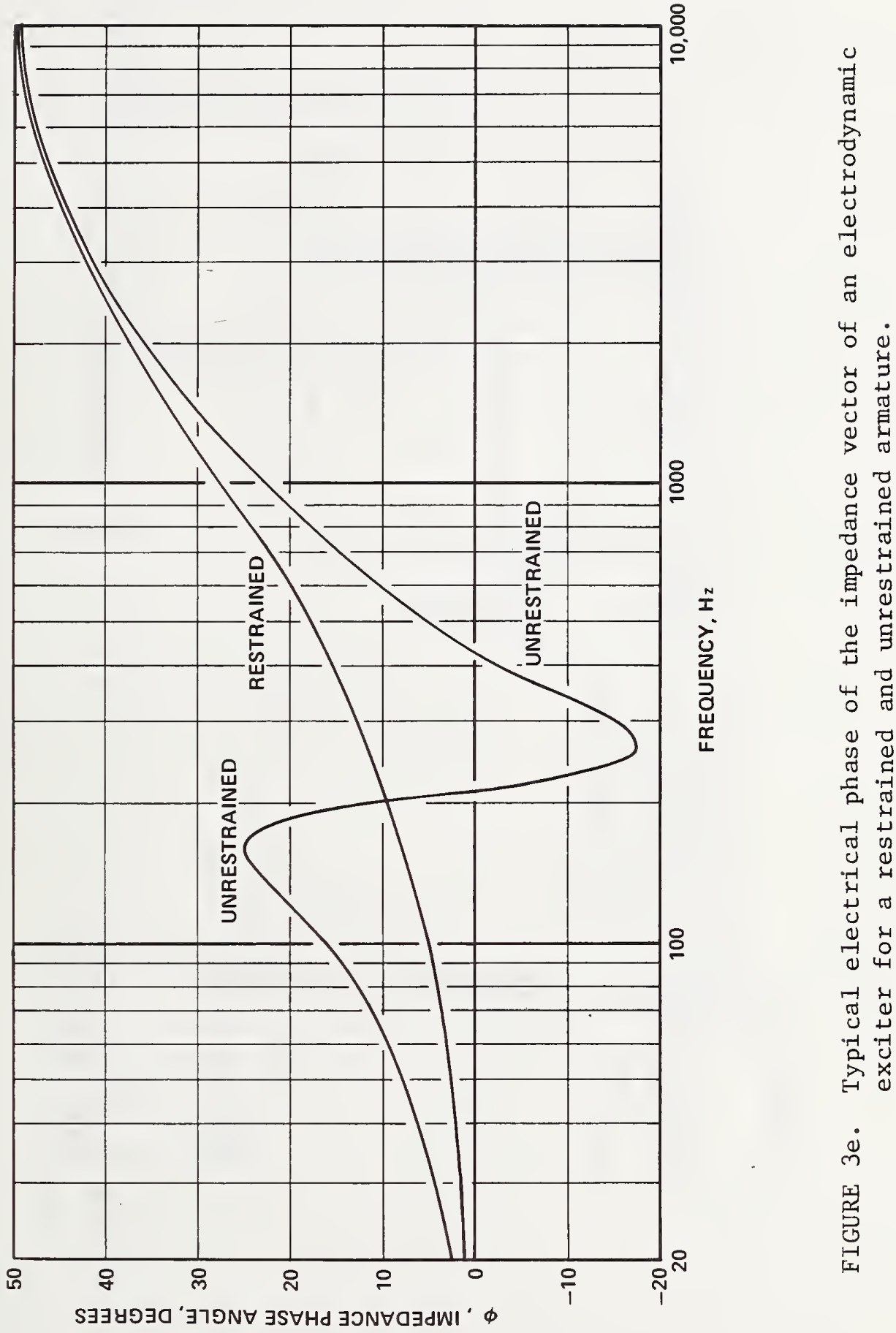


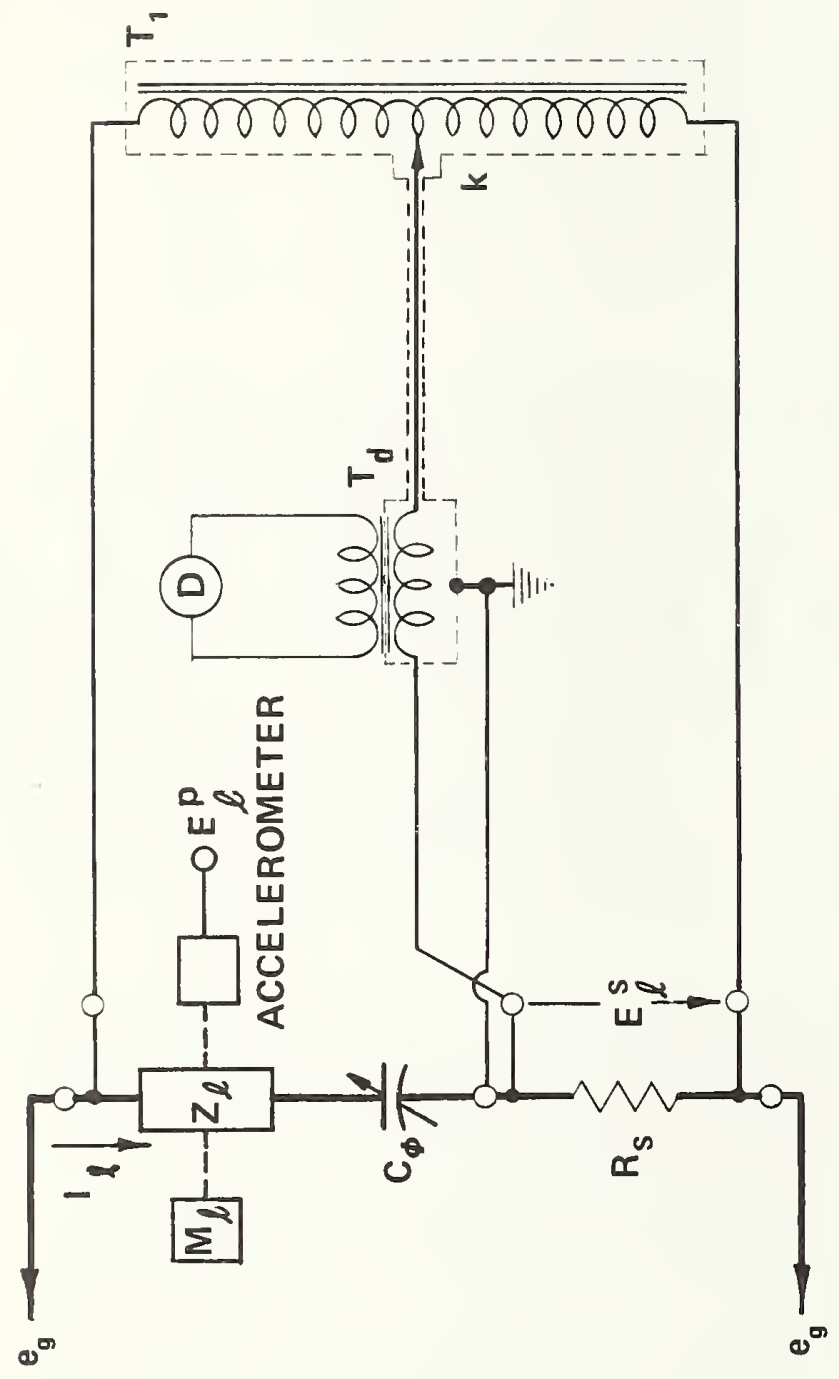

0

뜨를 


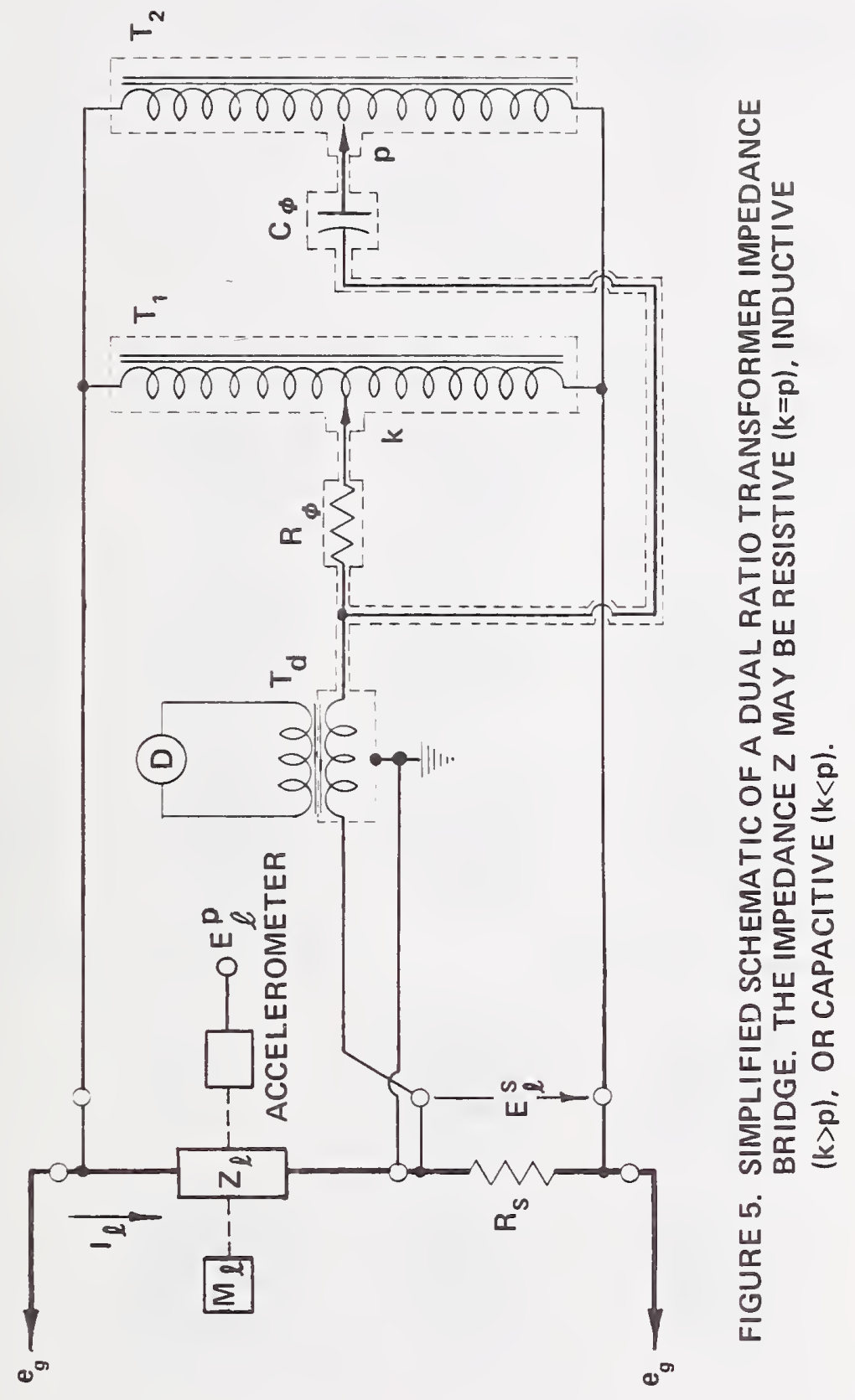




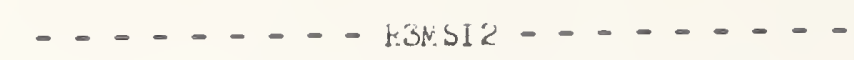

3-MASS SOLUIION HOK: 3 / 9 / 70 365010

\begin{tabular}{|c|c|c|c|c|}
\hline$K(1)=.363272$ & $K(2)=.362974$ & $x(3)=.362675$ & & \\
\hline$C(1)=37 \cdot 4675$ & $c(2)=37 \cdot 007$ & $c(3)=36 \cdot 659$ & & \\
\hline $\begin{array}{l}v(1,1)=71 \cdot 055 \\
31 \cdot 63\end{array}$ & & $V(1 \cdot 2)=50 \cdot 225$ & & $V(1,3)=$ \\
\hline $\begin{array}{l}v(2,1)=2879 \\
2879\end{array}$ & & $V(2,2)=2879$ & & $V(2,1)=$ \\
\hline$C(2,1)=0$ & $(212 \cdot 2)=0$ & $4(2,3)=0$ & & \\
\hline$k=998 \cdot 2$ & $k 1=4$ & & & \\
\hline$Y$ & $K(Y)$ & $X(Y)$ & $M A G \angle(Y)$ & $u(X)$ \\
\hline 1 & $7 \cdot 011 \approx 3$ & $4 \cdot 2623$ & $8 \cdot 20499$ & $31 \cdot 2972$ \\
\hline 2 & $7 \cdot .2 ธ ะ 7$ & $4 \cdot 30843$ & $8 \cdot 23675$ & $31 \cdot 5387$ \\
\hline 3 & $7 \cdot 02916$ & $4 \cdot 34933$ & $8 \cdot 26594$ & $31 \cdot 7474$ \\
\hline$Y$ IIFF & $K(Y)$ DIH & $X(Y)$ UILE & 'Z(Y) DIF' & $Q(Y)$ DIFE \\
\hline $1-2$ & $-9 \cdot 040 \approx 1 L-3$ & $-4 \cdot 61278 \mathrm{~b}-2$ & $4 \cdot 70053 t-2$ & $78 \cdot 9119$ \\
\hline $2-3$ & $-9 \cdot .8527 \mathrm{k}-3$ & $-4 \cdot .8995 z-2$ & $4 \cdot 18964 d-2$ & $77 \cdot 4759$ \\
\hline $3-1$ & $1 \cdot 81253 \mathrm{E}-2$ & $8 \cdot 72273 \mathrm{E}-2$ & $8 \cdot 88947 \mathrm{k}-2$ & $78 \cdot 2352$ \\
\hline MASS & SENS, MV/G & PHASE & ACCLL, G'S & VOLT KAIIO \\
\hline 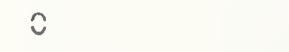 & $1 乞 \cdot .8837$ & - 636375 & $7 \cdot \hat{0} 4654$ & $2 \cdot 468=4 L-2$ \\
\hline $45 \cdot 18$ & $1 \hat{2} \cdot \widetilde{6} 687$ & . 653841 & $4 \cdot 98823$ & $1 \cdot 74453 \mathrm{~L}-2$ \\
\hline $135 \cdot 18$ & $10 \cdot .32$ & . 669295 & $3 \cdot 1529$ & 1. $09865 k-2$ \\
\hline
\end{tabular}

NOM SLNS $=10 \quad$ AVE SLNS $=10 \cdot 6615 \quad$ DLV FKH NOM= 614707

\begin{tabular}{|c|c|c|c|}
\hline MASS. TOTAL & DEV IM AVE & DEV IM NOM & \\
\hline $119 \cdot 463$ & $\cdot 220643$ & .836726 & \\
\hline $154 \cdot 643$ & $7 \cdot 18271 \mathrm{k}-2$ & .686975 & \\
\hline $244 \cdot 643$ & -.29247 & $\cdot 320439$ & \\
\hline$Y$ & MASS RAD & IHKED KAD & VOLI' KATIO \\
\hline 1 & $8 \cdot 23774$ & $3 \cdot 16648$ & $2 \cdot 468 \Omega 4 E-2$ \\
\hline 2 & $5 \cdot 48451$ & $6 \cdot 71856$ & $1 \cdot 74453 \mathrm{~L}-2$ \\
\hline 3 & $16 \cdot 4298$ & $3 \cdot 55261$ & 1. $.9865 \mathrm{k}-2$ \\
\hline
\end{tabular}

FIGURE 6a. Printout Data for Three-Mass Reciprocity Calibration (Test Number $365010, \mathrm{f}=1000 \mathrm{~Hz}$ ). 


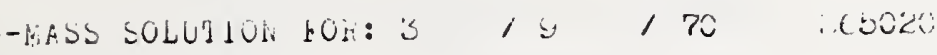

\begin{tabular}{|c|c|c|c|c|}
\hline$k(1)=.36326 . b$ & $n(2)=.362504$ & $\times 1: 31=.362606$ & & \\
\hline$c(1)=37 \cdot 403$ & $(: 12)=37 \cdot 00\}$ & $c(3)=3 c \cdot c b s$ & & \\
\hline $\begin{array}{l}v(1,1)=71 \cdot 06 \\
31 \cdot 63\end{array}$ & & $v(1,2)=50.23$ & & $\forall(1,3)=$ \\
\hline $\begin{array}{l}12,11=2879 \\
2879\end{array}$ & & $v(2,2)=28,7 y$ & & $v(2,1)=$ \\
\hline $4(2,1)=0$ & $u(2,2)=0$ & $6(2,3)=\imath$ & & \\
\hline$j=498 \cdot 2$ & $n 1=4$ & & & \\
\hline Y & $k(Y)^{\circ}$ & $X(Y)$ & $W A C<(1)$ & $4(1)$ \\
\hline 1 & $7 \cdot 01125$ & $4 \cdot 26225$ & $8 \cdot 20014$ & $31 \cdot 2961$ \\
\hline 2 & $7 \cdot 02038$ & $4 \cdot 30831$ & $8 \cdot 23694$ & $31 \cdot 5369$ \\
\hline 3 & $7 \cdot 02952$ & $4 \cdot 34033$ & $8.206<5$ & $31 \cdot 7461$ \\
\hline $\mathrm{IIFH}$ & $F(Y) \quad$ DIFE & $X(Y)$ UIFH & $\measuredangle(I)$ LIFE & $O(Y) \quad D I F F$ \\
\hline $1-2$ & $-9 \cdot 1: 3144 h-3$ & $-4 \cdot 606845-2$ & $4 \cdot \csc 646-2$ & $78 \cdot 7885$ \\
\hline $2-3$ & $-9 \cdot 1 \leq 660 k-3$ & $-4 \cdot 10159 \mathrm{~s}-2$ & $4 \cdot 20234 \overline{1}-2$ & $77 \cdot 4287$ \\
\hline $3-1$ & .013278 & $33 \cdot 708433 t-2$ & $8 \cdot 39818 E-2$ & $78 \cdot 1464$ \\
\hline MASS & SENS, MV/G & PHASE & $A C C E L, G ' S$ & WOL'I KATIO \\
\hline$\approx$ & $10 \cdot 0991$ & .637795 & 7.03629 & $2 \cdot 46822 \mathrm{k}-2$ \\
\hline $45 \cdot 18$ & $10 \cdot 0637$ & - 654524 & $4 \cdot 99118$ & .017447 \\
\hline $135 \cdot 18$ & $10 \cdot 0076$ & $\cdot 669382$ & $3 \cdot 16058$ & $1 \cdot-93656-2$ \\
\hline NOM SINS $=10$ & A.V SHES $=10 \cdot 0$ & 568 & DEV FKM NOH = & .568245 \\
\hline MASS, IOIAL & DEV FN AVE & DEV FW NON & & \\
\hline $110 \cdot 237$ & .420121 & •sSu754 & & \\
\hline $155 \cdot 417$ & . ¿GEsEs & .037496 & & \\
\hline $245 \cdot 417$ & -.4885979 & $7 \cdot 649775-2$ & & \\
\hline$y$ & WASS KAL & $I M Y E L K A L$ & VOL' KAIIO & \\
\hline 1 & $8 \cdot 23774$ & $s \cdot 1711$ & $2 \cdot 4 \in \varepsilon z 2 \mathrm{r}-2$ & \\
\hline 2 & $5 \cdot 48451$ & $6 \cdot 71459$ & $\cdot 017447$ & \\
\hline 3 & $16 \cdot 4098$ & $3 \cdot 5 \leq 397$ & $1.09865 \mathrm{t}-2$ & \\
\hline
\end{tabular}

FIGURE 6b. Printout Data for Three-Mass Reciprocity Calibration (Test Number 365020 , $f=1000 \mathrm{~Hz}$ ). 


\begin{tabular}{|c|c|c|c|c|}
\hline 3-MASS SOLUTION & TOR: 3 & $/ 70$ & 65030 & \\
\hline$K(1)=\cdot 363275$ & $K(2)=.36296$ & $K(3)=.362685$ & & \\
\hline$C(1)=37 \cdot 4685$ & $c(2)=37 \cdot c 085$ & $C(3)=36.661^{\circ}$ & & \\
\hline $\begin{array}{l}V(1.1)=71.06 \\
31.64\end{array}$ & & $V(1,2)=50.23$ & & $V(1,3)=$ \\
\hline $\begin{array}{l}V(2,1) \pm 2879 \\
2879\end{array}$ & & $V(2,2)=2879$ & & $V(2,1)=$ \\
\hline $0(2,1)=0$ & $0(2,2)=0$ & $0(2,3)=0$ & - & \\
\hline$F=998 \cdot 2$ & $\mathrm{RI}=4$ & & & - \\
\hline$Y$ & $R(X)$ & $X(Y)$ & MAG $2(Y)$ & $Q(Y)$ \\
\hline 1 & $7 \cdot 01094$ & $4 \cdot 26219$ & $8 \cdot 20485$ & $31 \cdot 2969$ \\
\hline 2 & $7 \cdot 0205$ & $4 \cdot 32826$ & $8 \cdot 23702$ & $31 \cdot 5361$ \\
\hline 3 & $7 \cdot \cong 2885$ & $4 \cdot 349 \approx 9$ & $8 \cdot 26555$ & $31 \cdot 7471$ \\
\hline$Y$ DIF & $R(Y) D I F F$ & $X(Y)$ DIFF & $Z(X)$ DIFI & $Q(Y) D I F$ \\
\hline $1-2$ & -.009556 & $-4 \cdot 60671 \mathrm{E}-2$ & $4 \cdot 70478 E-2$ & $78 \cdot 281$ \\
\hline $2-3$ & $-8 \cdot 35611 E-3$ & $-4 \cdot 08368 E-2$ & . $\triangle 41683$ & $78 \cdot 4357$ \\
\hline $3-1$ & $1 \cdot 79121 \Sigma-2$ & • ↔869へ4 & $8.87307 E-2$ & $78 \cdot 3537$ \\
\hline MASS & SEMSOAN/G & PHASE & ACCEL, G'S & VOLT KATIO \\
\hline 0 & $10 \cdot 0634$ & . 649216 & $7 \cdot .66123$ & $2 \cdot 46822 \mathrm{E}-2$ \\
\hline $45 \cdot 18$ & $10 \cdot \approx 816$ & . 65196 & 4.98236 & $\cdot 017447$ \\
\hline $135 \cdot 18$ & $10 \cdot 0747$ & - 654374 & $3 \cdot 14053$ & $1 \cdot \cong 9899 E-2$ \\
\hline NOM SEUS = 10 & AYS SEWS $=10.0$ & 732 & DEV FKM NOM= & - 732314 \\
\hline MASS.TORAL & DEV IT $\triangle Y Z$ & DEV FM NOM & & \\
\hline $108 \cdot 281$ & $-9 \cdot 758072-2$ & - 634019 & & \\
\hline 153.461 & $8 \cdot 27671 \mathrm{~L}-2$ & $\cdot 815687$ & & \\
\hline $243 \cdot 161$ & $1 \cdot 48136 \mathrm{P}-2$ & - 747236 & & \\
\hline$Y$ & MASS RUD & IMPED KAD & VOLT KATIO & \\
\hline 1 & 8.23774 & $3 \cdot 15989$ & $2 \cdot 46822 E-2$ & \\
\hline 2 & $5 \cdot 48151$ & $6 \cdot 72648$ & . 017447 & \\
\hline 3 & $\begin{array}{l}16 \cdot 4008 \\
\ldots . . .\end{array}$ & $\begin{array}{l}3.56659 \\
-.-.-\end{array}$ & $\begin{array}{l}1 \cdot \approx 9899 \mathrm{E}-2 \\
----\cdots\end{array}$ & \\
\hline
\end{tabular}

FIGURE 6c. Printout Data for Three-Mass Reciprocity Calibration (Test Number $365030, f=1000 \mathrm{~Hz}$ ). 


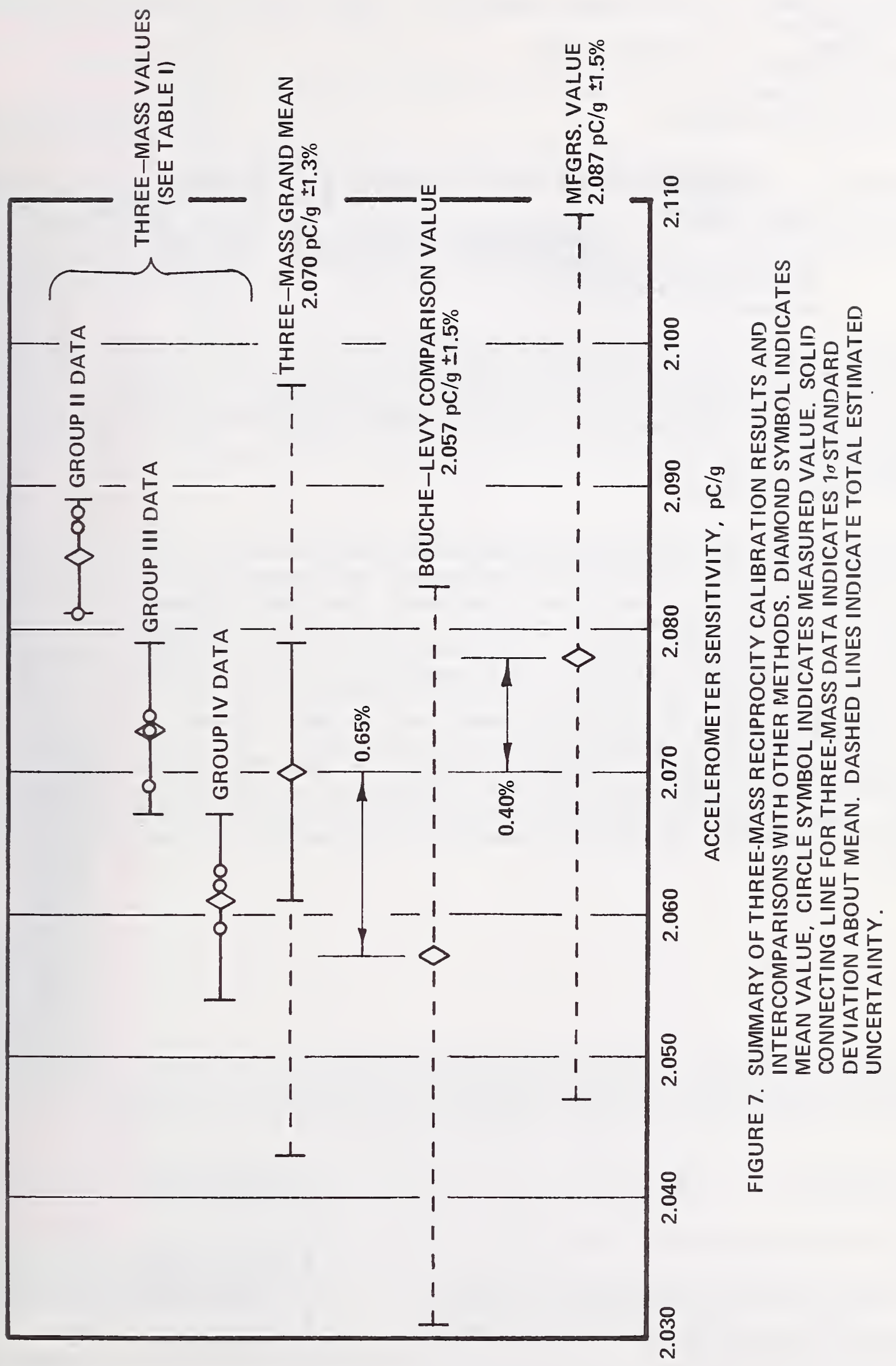


HBS-I14A (REV. 7-73)

\begin{tabular}{|c|c|c|c|}
\hline $\begin{array}{l}\text { W.S. DEPT. OF COMM. } \\
\text { BIBLIOGRAPHIC DATA } \\
\text { SHEET }\end{array}$ & $\begin{array}{l}\text { 1. PUBLICATION OR REPORT NO. } \\
\text { NBSIR-74-481 }\end{array}$ & $\begin{array}{l}\text { 2. Gov't Accession } \\
\text { No. }\end{array}$ & 3. Recipient's Accession No. \\
\hline \multicolumn{3}{|c|}{$\begin{array}{l}\text { 4. TITLE AND SUBTITLE } \\
\text { Absolute Calibration of Vibration Standards by the Three- } \\
\text { Mass Reciprocity Method }\end{array}$} & $\begin{array}{l}\text { 5. Publication Date } \\
\text { Apri1 } 1974 \\
\text { 6. Performing Organizarion Code }\end{array}$ \\
\hline \multirow{2}{*}{\multicolumn{3}{|c|}{$\begin{array}{l}\text { 7. AUTHOR(S) } \\
\text { John D. RambOZ } \\
\text { PATIONAL BUREAU OF STANDARDS } \\
\text { DEPARTMENT OF COMMEREE } \\
\text { WASHINGTON, D.C. } 20234\end{array}$}} & $\begin{array}{l}\text { 8. Performing Organ. Repore No. } \\
\text { NBSIR } 74-481\end{array}$ \\
\hline & & & 10. Project/Task/Work Unit No. \\
\hline \multirow{2}{*}{\multicolumn{3}{|c|}{$\begin{array}{l}\text { 12. Sponsoring Organization Name and Complete Address (Street, City, State, ZIP) } \\
\text { Metrology Engineering Center, Bureau of Naval Weapons Represent- } \\
\text { ative, Pomona, California } 91766 \text {; the Aerospace Guidance and } \\
\text { letrology Center, Newark Air Force Station, Newark, Ohio } 43055 \text {; } \\
\text { and the Metrology and Calibration Center, Redstone Arsenal, } \\
\text { Alabama } 35809\end{array}$}} & $\begin{array}{l}\text { 13. Type of Report \& Period } \\
\text { Covered } \\
\text { Final }\end{array}$ \\
\hline & & & 14. Sponsoring Agency Code \\
\hline \multicolumn{4}{|c|}{$\begin{array}{l}\text { 15. SUPPLEMENTARY NOTES } \\
\text { CCG Project CCG } 69-15\end{array}$} \\
\hline \multicolumn{4}{|c|}{$\begin{array}{l}\text { 16. A BSTRACT (A 200-word or less factual summary of most significant information. If document includes a significant } \\
\text { bibliography or literature survey, mention it here.) Reciprocity calibrat:Lon of electrodynamic vibration } \\
\text { exciters is reviewed. A new method is proposed. The theory for the new Three-Mass } \\
\text { reciprocity calibration method is developed. The process requires that the electrical } \\
\text { impedance of the exciter's drive coil be measured for three added masses separately } \\
\text { mounted on the exciter's armature. The sensitivity of the accelerometer mounted in } \\
\text { the armature is solved in terms of a change of electrical impedance for a change of } \\
\text { mass, voltage ratio, electrical resistance, and frequency. A set of } 38 \text { measurements } \\
\text { were made at } 1000 \mathrm{~Hz} \text { to experimentally verify the theory. The value of sensitivity } \\
\text { was } 2.070 \mathrm{pC} / \mathrm{g} \pm 1.3 \text { percent. This agreed to within about. t0.65 percent of a transfer } \\
\text { calibration from. Bouche-Levy calibrated standards and the manufacturer's estimated } \\
\text { value. Measurements were made to verify the theory; improvement to an uncertainty } \\
\text { of about } \pm 0.2 \text { percent is ultimately possible in the absolute calibration using this } \\
\text { method. }\end{array}$} \\
\hline
\end{tabular}

17. KEY WORDS (six to twelve entries; alphabetical order; capitalize only the first letter of the first key word unless a proper name; separated by semicolons) Absolute calibration; accelerometers; calibration; reciprocity calibration; vibration exciters; vibration pickups; vibration standards.

18. AVAILABILITY

For Official Distribution. Do Not Release to NTIS

D Order From Sup. of Doc., U.S. Government Printing Office W'ashington, D.C. 20402, SD Cat. No. C13

X] Order From Nacional Technical Information Service (NTIS) Springfield, Virginia 22151

\begin{tabular}{|l|c|}
\hline $\begin{array}{l}\text { 19. SECURITY CLASS } \\
\text { (THIS REPURT) }\end{array}$ & 21. NO. OF PAGES \\
UNCL ASSIFIED & 48 \\
\hline $\begin{array}{l}\text { 20. SECURITY CLASS } \\
\text { (THIS PAGE) } \\
\text { UNCLASSIFIED }\end{array}$ & 22. Price \\
\hline
\end{tabular}

